\title{
CONGESTIÓN URBANA Estudio y transformación urbana de San Victorino, Bogotá
}

\author{
David Cortés López \\ Universidad Nacional de Colombia \\ Director: PhD. Camilo Pinilla \\ davidcortesl@gmail.com
}

\section{RESUMEN}

La congestión urbana se refiere al resultado de un proceso de acumulación de materia en el espacio, y a la relación de esta configuración con la sociedad. El presente artículo tiene como objetivos, entender y transformar, por medio del análisis y diseño urbano, el problema de la congestión urbana en el sector de San Victorino, ubicado en la ciudad de Bogotá. Los objetivos se desarrollaron con una metodología aplicada, a través de un componente principal: configuración espacial; y dos componentes complementarios: retrospectiva y radiografía urbana. Como resultado se reveló el proceso histórico de transformación urbana que llevó a la congestión de San Victorino, también se evidenció la influencia de la configuración espacial en la sociedad y en la congestión urbana de San Victorino; así mismo se propusieron estrategias de diseño, que permiten visualizar y evaluar diferentes escenarios, como alternativas de transformación urbana para contrarrestar gradualmente el problema de la congestión.

Palabras Clave: Congestión urbana, configuración espacial, diseño urbano, San Victorino.

\begin{abstract}
Urban congestion refers to the result of a process of accumulation of matter in space, and the relationship of this configuration with society. The objective of this article is to understand and transform, through urban analysis and design, the problem of urban congestion in the San Victorino sector, located in the city of Bogotá. The objectives were developed with an applied methodology, through a main component: spatial configuration; And two complementary components: retrospective and urban radiography. As a result, the historical process of urban transformation that led to the congestion of San Victorino was revealed, also the influence of spatial configuration on society and the urban congestion of San Victorino was evidenced; likewise, design strategies were proposed, which allow visualizing and evaluating different scenarios, as alternatives for urban transformation to gradually counteract the problem of congestion.
\end{abstract}

Keywords: Urban congestion, spatial configuration, urban design, San Victorino. 


\section{INTRODUCCIÓN}

El siguiente artículo es producto del trabajo final de Maestría en Diseño Urbano: Congestión Urbana, estudio y transformación urbana de San Victorino, Bogotá; el trabajo surge del interés por entender la generación del fenómeno de la congestión urbana, y como este influye, o es influido, por la configuración espacial de la ciudad y su relación con la sociedad. Así mismo, el interés se enfoca en la búsqueda de estrategias de diseño urbano, que permitan disminuir el impacto, o eliminar el problema de la congestión.

\subsection{El tema y el problema}

El tema de la congestión en el espacio urbano se refiere al fenómeno que ocurre como resultado de un proceso histórico de acumulación de elementos materiales e inmateriales que componen la ciudad. El tema se aborda desde la identificación de los límites del espacio, como una condición que restringe el volumen de ocupación, que es factible de configurar de diversas formas, que determinan la capacidad de movimiento dentro del espacio. Cuando el volumen llega al límite de capacidad del espacio o su configuración propaga concentraciones acentuadas que dificultan el confort de la gente, este momento se identifica como el problema de la congestión. Con base en lo anterior se construyó la siguiente pregunta principal, como eje central del trabajo:

\section{¿Cómo entender y transformar la Congestión Urbana en San Victorino desde un enfoque socio- espacial?}

En relación a la pregunta se proponen los siguientes objetivos que buscan entender el fenómeno para posteriormente iniciar la etapa propositiva del proceso de diseño:

- Demostrar cómo es posible entender el espacio urbano de un área congestionada de Bogotá.

- Ejemplificar como transformar la forma urbana de un área congestionada de Bogotá.

Como hipótesis para dar respuesta a la pregunta y objetivos, se argumenta que la acumulación de elementos o masas en el espacio de una ciudad tiene límites, solo es posible ubicar en este determinada cantidad de volumen; efecto que tiene relación directa con la gente, debido a que nos movemos en el espacio, y dependiendo de su configuración, en relación "lleno-vacío", nos es permitido o restringido desplazarnos. En este sentido la acumulación excesiva de personas en el espacio, hipotéticamente es generada por la forma como está configurado el espacio.

>1. Esquema de congestión. Elaboración propia

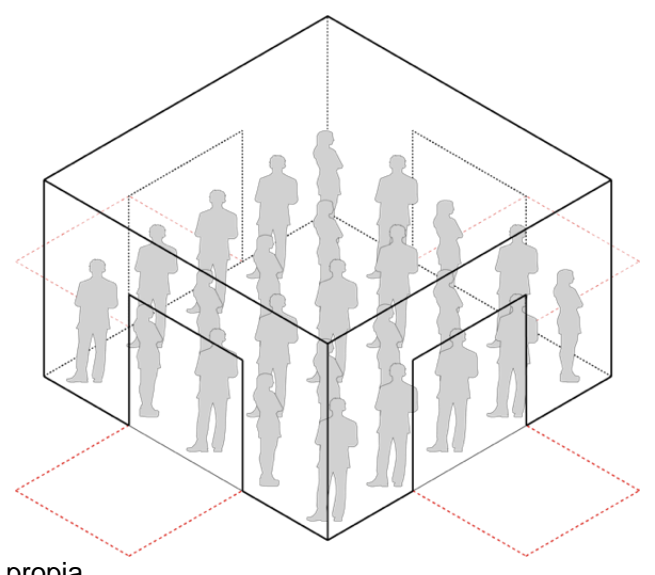

\section{2 Área de estudio}

Como lugar de estudio y transformación para dar respuesta a la pregunta central, se seleccionó el sector de San Victorino ubicado en el centro de Bogotá, que desde el siglo de fundación de la ciudad, se ha formado 
como uno de los centros urbanos de comercio más importantes del país convirtiéndolo en un sector donde la congestión se manifiesta con gran intensidad.

San Victorino ha representado para la ciudad un lugar de acumulaciones, vocación comercial y diversas actividades. Su localización estratégica de acceso al centro de la ciudad desde el occidente, ha servido de puerta de entrada de escala mundial desde la colonia y fundación de la ciudad. Por allí han llegado y salido diversidad de productos y visitantes que han convertido el espacio de San Victorino en uno de los lugares más concurridos y congestionados de la ciudad.

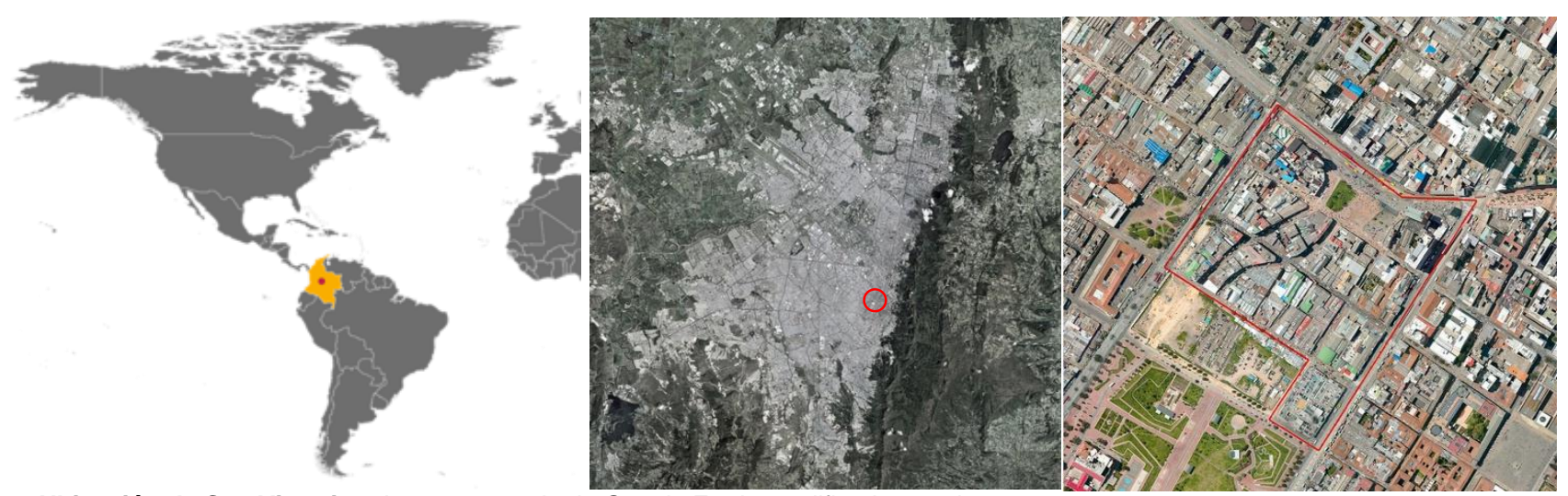

> 2. Ubicación de San Victorino. Imagen tomada de Google Earth, modificada por el autor 2016.

El sector de San Victorino tiene una influencia morfológica de la trama urbana fundacional de la ciudad, que es cortada por vías principales que atraviesan la ciudad de oriente a occidente y norte a sur, haciendo del lugar un punto de llegada estratégico para los diferentes medios de transporte. La trama urbana interna del sector tiene una particularidad generada por el paso del rio canalizado de San Francisco, que genera identidad y diversidad a la forma del lugar, que es influenciada por el damero español desde su fundación. El sector se ubica en un espacio intermedio entre una sucesión de plazas ( Bolívar, San Victorino, Mártires y España ) que han recibido los mercados y el comercio a través de la historia de Bogotá.

"Desde la colonia San Victorino ha sido el punto más intenso de Bogotá. En ningún otro lugar del país se venden más mercancías que allí -dice Niño-, la señora que va a hacer la fiesta de su hija compra ahí, al igual que los comerciantes de Ibagué, Villavicencio, de fuera de la ciudad. Se trata de una plaza cuyo camino (hoy calle 13) hacia Facatativá, Fontibón, Honda, Cartagena y Madrid, España, era el cordón umbilical del país con el Imperio y con el mundo, y por eso siempre hubo congestión y ladrones". ${ }^{1}$

\subsection{Marco teórico}

Como consideración teórica este trabajo se orienta a abordar el fenómeno de la Congestión en el Espacio Urbano, desde la relación espacio-sociedad. En general la relación espacio-sociedad ha sido mayormente estudiada de manera empírica, desde campos y dimensiones que estudian al ser humano: como la antropología o la sociología, que miran hacia el efecto de la vida social en la organización espacial; por ejemplo los estudios de, Claude Levi -Strauss, (Strauss, 1967); Edward T. Hall, (Hall, 1969); o Bourdieu, (1973).

Adicionalmente, dentro de sus matices, esta relación de espacio - sociedad ha sido estudiada por autores más cercanos a la disciplina del diseño urbano, como: el periodista William H. Whyte, (Whyte, 1980); la pensadora Jane Jacobs, (Jacobs, 2013); y arquitectos como: Kevin Lynch (Lynch, 1960); Gordon Cullen (Cullen, 1974); Rem Koolhaas, (Koolhaas, 1994); y Jan Gehl, (Gehl, Cities for people, 2010); entre otros. Todos con aportes diversos relacionados al campo de estudio, sin embargo, poco se ha abordado la investigación específicamente desde la lógica del espacio, es decir, de forma autónoma.

1 Tomado de Articulo, El Bronx no es ningún accidente. Carlos Niño, Revista Arcadia, 2016. 
En 1984, Bill Hillier con Julienne Hanson escribieron el libro The Social Logic of Space (Hiller \& Hanson, 1984), donde exponen una nueva teoría y un esquema de métodos de análisis, que buscan entender desde el estudio del espacio, la relación entre espacio y vida social, demostrando cómo las formas construidas y la organización espacial, tienen consecuencias sociales.

Los metodos desarrollados por Hillier y Hanson, estan enmarcados en la "sintaxis del espacio", estrategia que permite leer el espacio y predecir la concentración de la gente en la estructura espacial de la ciudad, convirtiendose así en una herramienta teórica y procedimental que enrriquece y complementa el proceso de entender y transformar la congestión.

Para el caso de este trabajo, se busca desde el ambito del diseño urbano, en la relación espacio - sociedad; entender como la configuración del espacio puede ser generadora del problema de la congestión, y así mismo, como la configuración puede minimizar o erradicar el problema. Para esta busqueda el trabajo se basa en las medidas propuestas en la teoría de Bill Hillier, que predicen hacia donde vamos ( integración ) y por donde nos movemos ( elección ); permitiendo evaluar y predecir la formación de acumulaciones y por ende de la congestión.

Adicional a la teoría de Hillier se consultó una serie de fragmentos de diferentes libros incluidos en la bibliografía, para desarrollar la retrospectiva y radiografía, que indagaron en la historia de San Victorino y que sirvieron como referencia para entender la aparición de la congestión en el espacio urbano.

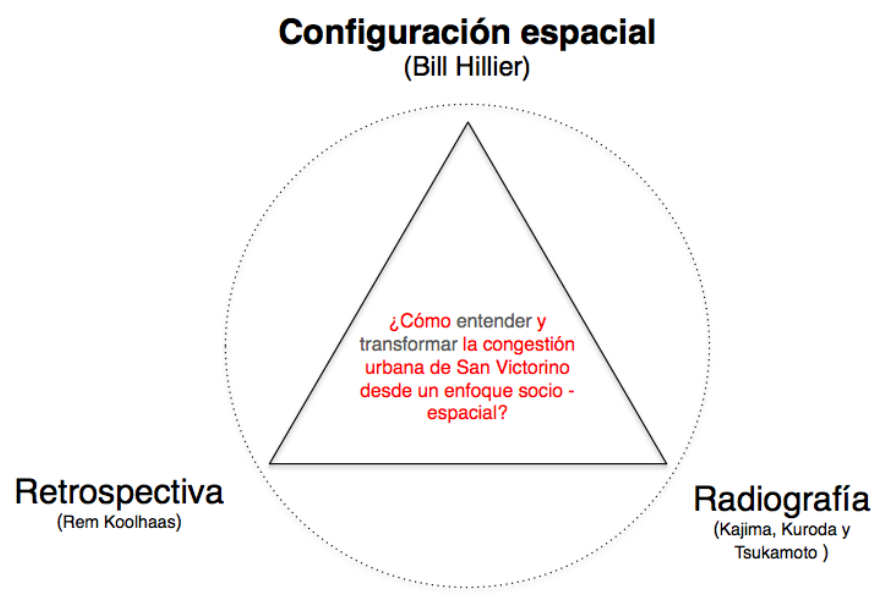

> 3. Esquema teórico. Elaboración propia

El gráfico anterior muestra como se articulan las teorías y estrategias escogidas de manera cíclica, para responder a la pregunta principal del trabajo.

\subsection{Metodología}

La estrategia empleada para responder a la pregunta principal es la aplicación de teorías y métodos compatibles que se organizan en un componente principal: La configuración urbana; y dos complementarios: retrospectiva y radiografía urbana 


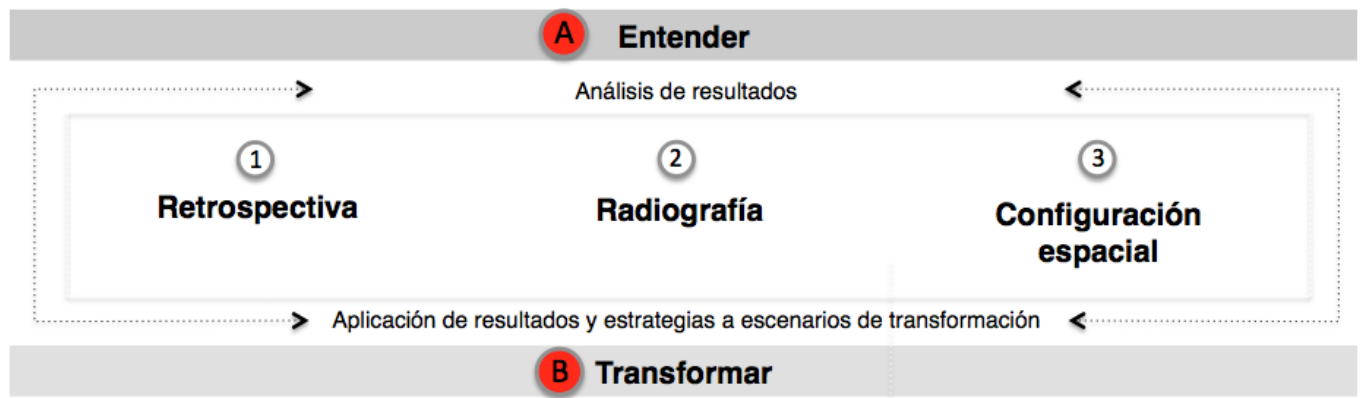

>4. Articulación cíclica entre metodología y objetivos.

A continuación se definen los componentes de la estretagia seleccionada:

- Componente principal, Configuración espacial (conjunto de métodos de la teoría de Space Syntax): Estudio y análisis de la estructura espacial urbana, que tiene implicaciones en el comportamiento de la gente, permitiendo predecir por donde y hacia donde nos desplazamos, evidenciando así, en donde se pueden presentar acumulaciones que generan congestión.

- Componente secundario, Retrospectiva (método retrospectivo): Investigación y análisis en restrospectiva, aplicados al área de estudio, para entender los momentos de transformación urbana, y como estos se han relacionado con el fenómeno de la congestión urbana en San Victorino.

- Componente secundario, Radiografía urbana: Se refiere al método utilizado para identificar el funcionamiento actual de la forma construida en el área de estudio; elaborando una caracterización estadística, y clasificación tipológica, que permite identificar efectos de la congestión y sirve como insumo para la transformación o retroactividad de elementos en el lugar.

\section{ENTENDER EL CONCEPTO Y FORMULACIÓN DE ESTRATEGIAS}

En la articulación ciclica de la metodología y objetivos, como primera acción se avanzó con el análisis urbano, en el marco de los tres componentes de la metodología expuesta, permitiendo entender como surge la congestión en San Victorino. Posteriormente en articulación con el análisis elaborado en los tres componentes ${ }^{2}$ abordados para entender y transformar el problema de la Congestión en el espacio Urbano, se construyeron siete estrategias que buscan servir de fundamento en la transformación urbana de áreas congestionadas como es el caso del área de estudio.

En la tabla 1 se muestra un cuadro lógico que presenta la forma como se vinculan las siete estrategias de transformación urbana para San Victorino, en relación a los componentes con los cuales se ha construido este trabajo.

\footnotetext{
${ }^{2}$ Retrospectiva, Radiografía y Configuración espacial
} 


\begin{tabular}{|c|c|c|c|c|}
\hline Problema & Tema & Objetivos & Estratégias & Acciones \\
\hline \multirow{10}{*}{$\begin{array}{l}\text { Congestión en el } \\
\text { espacio urbano }\end{array}$} & \multirow{3}{*}{$\begin{array}{l}\text { Retrospectiva } \\
\text { (memoria) }\end{array}$} & \multirow{3}{*}{$\begin{array}{c}\text { Realzar los elementos } \\
\text { históricos relevantes } \\
\text { en el nuevo conjunto }\end{array}$} & \multirow{3}{*}{$\begin{array}{l}\text { 1. Abstracción y } \\
\text { retroactividad de } \\
\text { elementos funcionales y } \\
\text { hechos, que han } \\
\text { construido la memoria de } \\
\text { San Victorino }\end{array}$} & $\begin{array}{l}\text { Reinterpretación de hechos históricos (p.e. Terminal, puerto, } \\
\text { mercado, caminos) }\end{array}$ \\
\hline & & & & Potenciar elementos naturales históricos como el Río San Francisco \\
\hline & & & & $\begin{array}{l}\text { Reinterpretar esencia de actividades actuales (p.e. Madrugón, } \\
\text { textiles, etc.) }\end{array}$ \\
\hline & \multirow{2}{*}{$\begin{array}{c}\text { Radiografía } \\
\text { (situación actual) }\end{array}$} & \multirow{2}{*}{$\begin{array}{l}\text { Caracterizar el lugar } \\
\text { de estudio en relación } \\
\text { a la congestión }\end{array}$} & $\begin{array}{l}\text { 2. Optimización del } \\
\text { programa }\end{array}$ & $\begin{array}{c}\text { Replantear la organización del programa en relación a las lógicas de } \\
\text { las dinámicas actuales y propuestas. (Logística) }\end{array}$ \\
\hline & & & $\begin{array}{l}\text { 3. Probabilidades de } \\
\text { gestión }\end{array}$ & $\begin{array}{l}\text { Relacionar la configuración espacial del área, con el cálculo de } \\
\text { prefactibilidad económica estática que haga posible el proyecto. }\end{array}$ \\
\hline & \multirow{5}{*}{$\begin{array}{l}\text { Configuración } \\
\text { Espacial }\end{array}$} & \multirow{5}{*}{$\begin{array}{l}\text { Reconfigurar y } \\
\text { optimizar la forma } \\
\text { urbana }\end{array}$} & 4. Conectar & $\begin{array}{l}\text { Creación de conectores a espacios receptores potenciales (Parque } \\
\text { Tercer Milenio, Voto nacional, Plaza España, Centro Histórico) }\end{array}$ \\
\hline & & & 5. Desocupar & $\begin{array}{l}\text { Reducción de la ocupación de espacio público, garantizando el área } \\
\text { construida existente, haciendo uso del espació aereo y de subsuelo. }\end{array}$ \\
\hline & & & \multirow[t]{2}{*}{ 6. Fluidez del tejido } & $\begin{array}{c}\text { Configuración de un tejido urbano fluido, que integre a San Victorino } \\
\text { en sentido oriente - occidente y norte - sur; por medio de espacios } \\
\text { conectores e integrados. (P.e. plazas, calles, pasajes plataformas, } \\
\text { puentes, etc.) }\end{array}$ \\
\hline & & & & $\begin{array}{c}\text { Optimizar conexiones intermodales en relación a los análisis de } \\
\text { accesibilidad y elección para lograr fluidez }\end{array}$ \\
\hline & & & 7. Flexibilidad espacial & $\begin{array}{l}\text { Dimensionar espacios en relación a las actividades actuales que } \\
\text { han sido cambiantes; y a posibles cambios futuros generadores de } \\
\text { congestión }\end{array}$ \\
\hline
\end{tabular}

>Tabla 1. Vinculación de los componentes del trabajo. Elaboración propia

\subsection{Retrospectiva}

En primer lugar, para entender la congestión en San Victorino, se dirige una mirada en retrospectiva, que revisa como se ha generado el fenómeno a través de la historia, y en este periodo, como se ha comportado en relación con la forma de la ciudad y la sociedad. La retrospectiva tiene la función de identificar y describir los elementos y momentos principales de transformación urbana que han tenido influencia en la congestión de San Victorino, desde la colonia.

Con el ejercicio de retrospectiva se encontró implícita la congestión en diversos aspectos, el primero y quizá el más importante en este marco histórico, es que la congestión no surgió de manera esporádica, si no, se construyó a partir de la suma de una serie de momentos en el tiempo, que en este trabajo sumaron diecinueve hechos y XVII componentes de transformación, construidos a lo largo de más de cuatrocientos años de historia. 


\section{Retrospectiva}

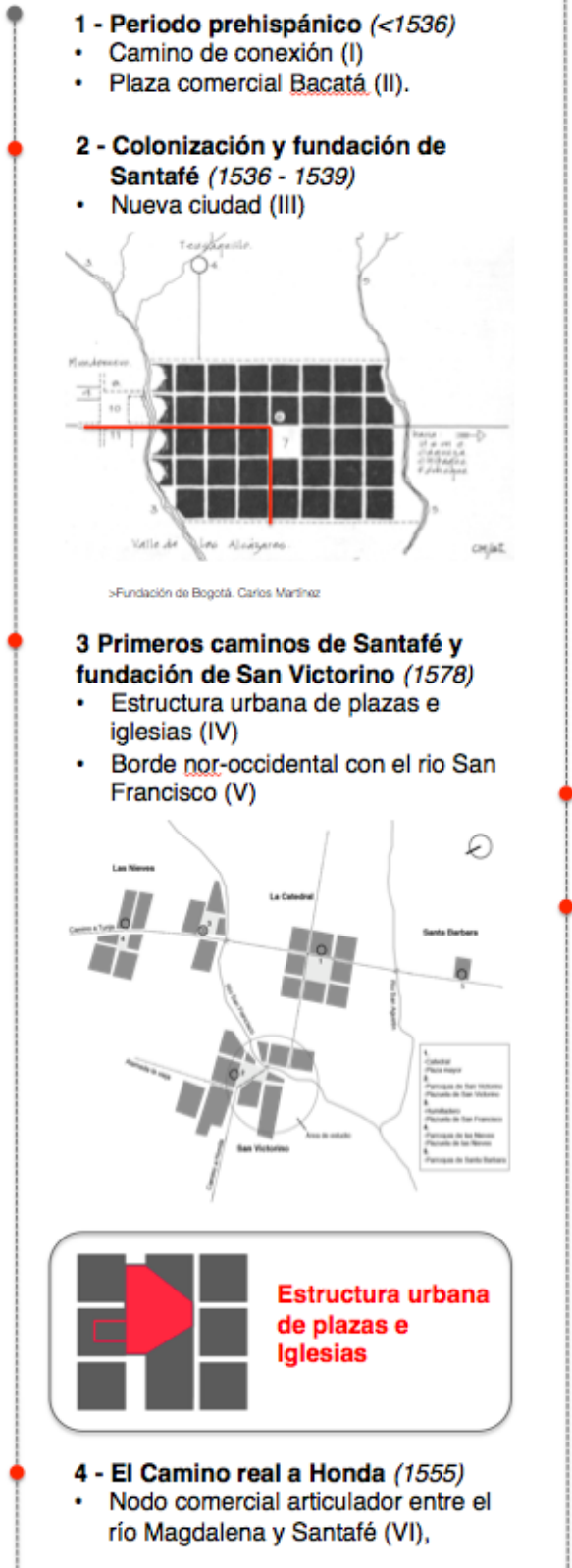

12 - La Avenida Jiménez de Quezada, la ampliación de la Avenida Colón; y la consolidación de plaza para estacionamientos y terminal de transporte (1930-1946) 330.312 habitantes en 1938

- Patrón de ensanchamiento de vías (XI)

- Estacionamiento de los vehículos públicos y privados (XII)
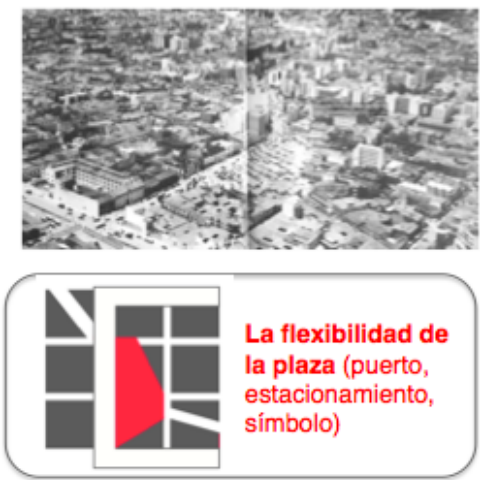

\section{1 - Estacionamiento de} automóviles (1936) 224.000 habitantes en 1929

\section{0 - Centenario de la}

independencia (1910)

100.000 habitantes en 1905 ,

145.000 habitantes en 1918

- Nuevos sistemas urbanos $(\mathrm{X})$

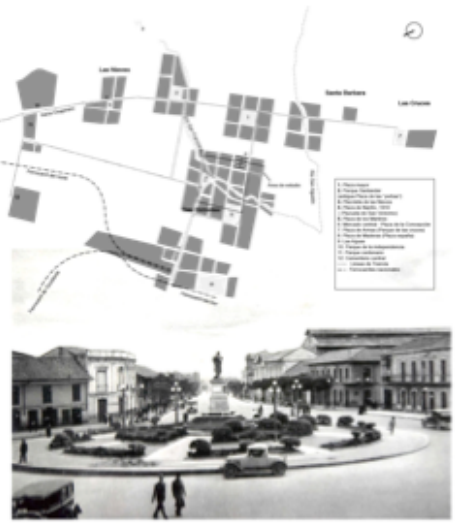

13 - Avenida Caracas (1933)

14 - El Bogotazo, incendios en la Zona (1948)

500.000 habitantes en 1945, N. Murcia

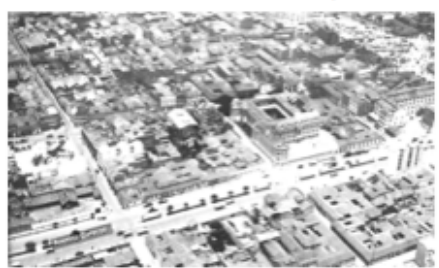

15 - Carrera Décima (1952 - 1957)

648.324 habitantes en 1951

- Isla entre avenidas (XIII)
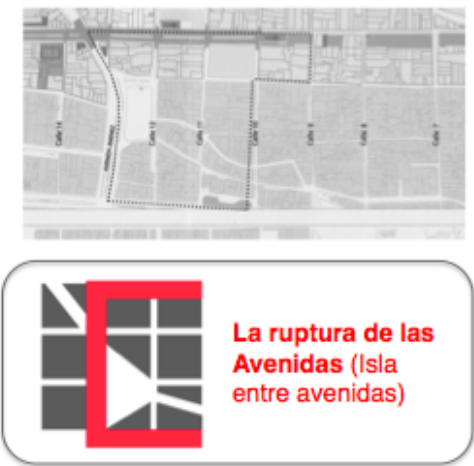

16 - Galerías Antonio Nariño (1962)

1.697.311 habitantes en 1964

- Módulos comerciales organizados en el espacio público XIV
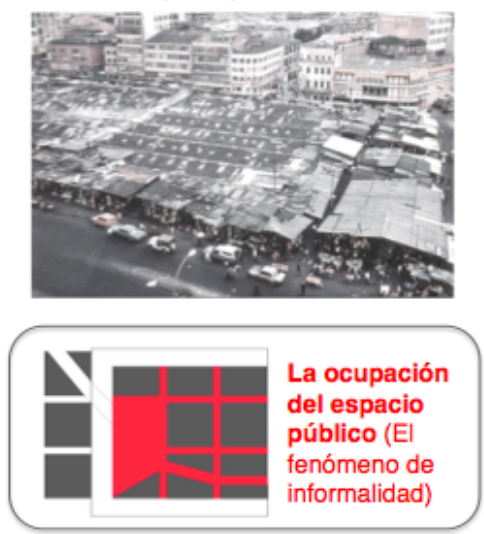


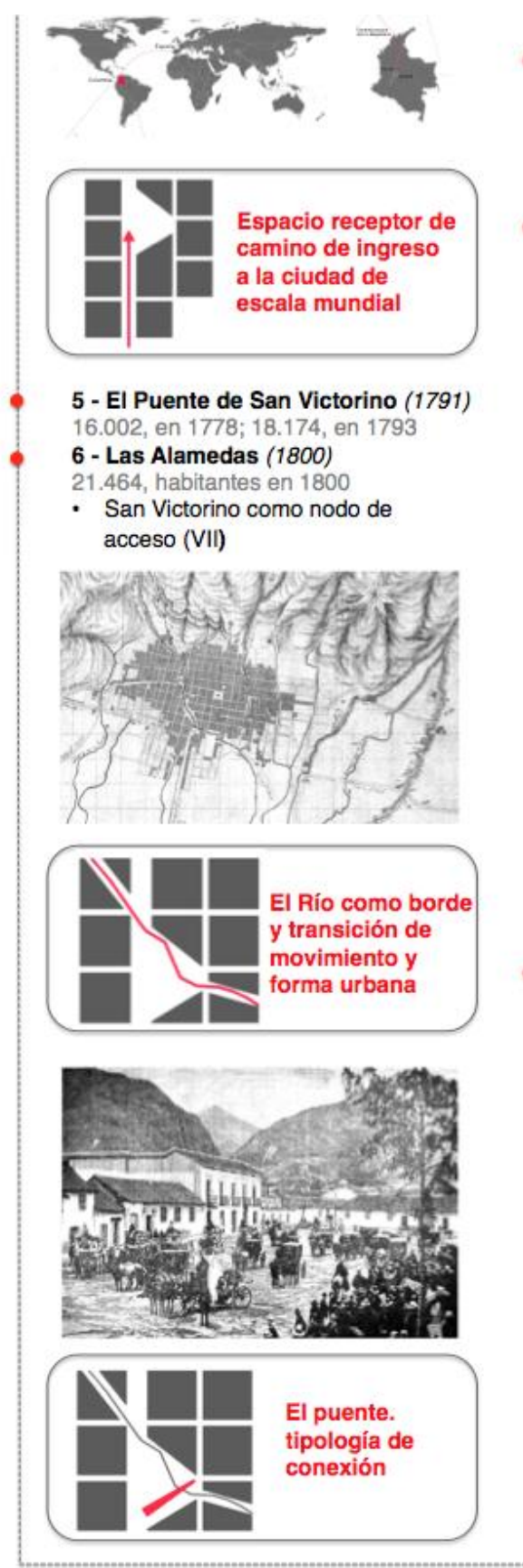

9 - Los Mercados (1864)

70.000 habitantes en 1885 , Silvia

Arango; 84.723 habitantes en 1881 ,

Vargas y Zambrano

- Mercado en espacio público y el mercado cubierto (IX)

8 - La Independencia (1810) 36.465 en $1832 ; 40.086$ en 1843
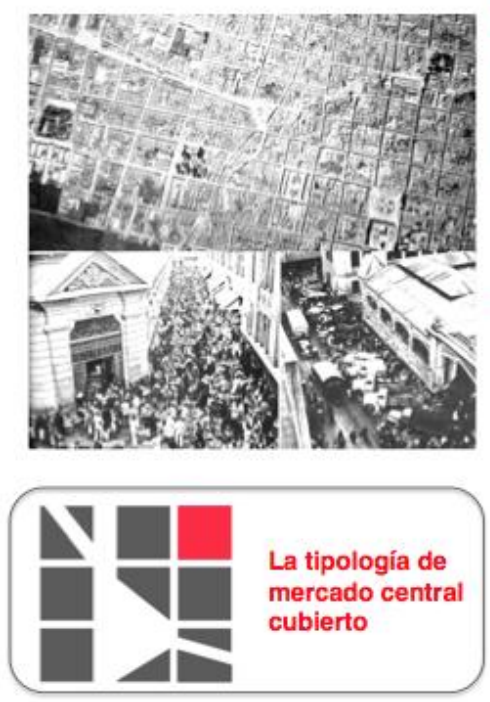

\section{7 - El acueducto y la pila de San} Victorino (1803)

- Pila para el aprovisionamiento de agua (VIII).
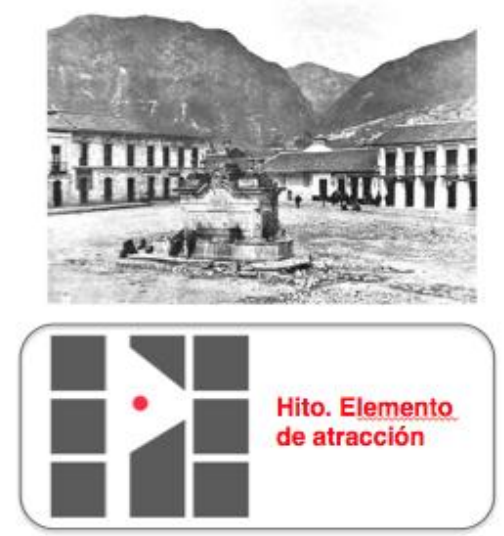

17 - Renovación urbana: Proyecto Tercer Milenio y Plaza de San Victorino (1998)

4.225.649 habitantes en 1985; y

5.699.655 habitantes en 1995

- Proyecto de renovación urbana XV
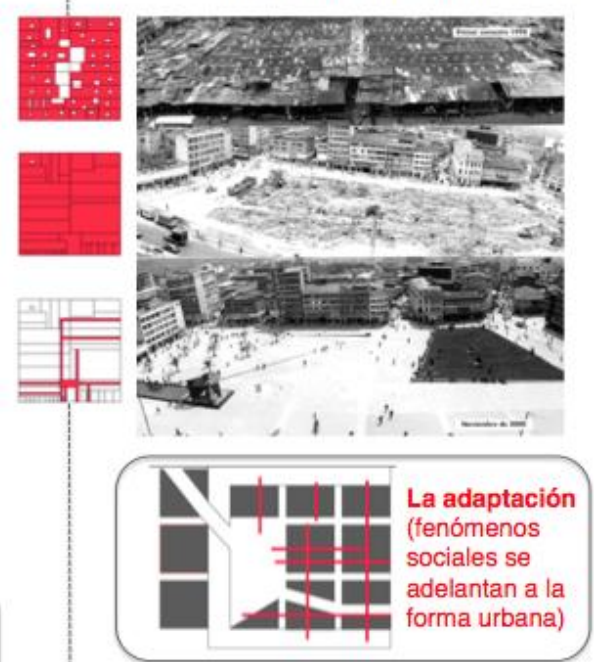

18 - Proyecto Centro

Internacional de Comercio

Popular San Victorino (2008)

6.840.116 habitantes en 2005

- Mutaciones de características emergentes XVI

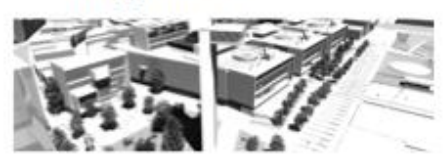

19 - Plan parcial de renovación urbana (2016)

7.878.783 habitantes en 2015 y 8.380 .801 en 2020

- "La Cultura de la congestión" XVII

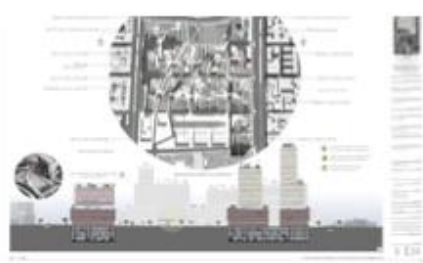

> 5. Retrospectiva de momentos históricos de transformación urbana en San Victorino.

La identificación de estos hechos y componentes de transformación, se resumieron a diez esquemas históricos ${ }^{3}$, que tuvieron participación en la generación de congestión y solución gradual al problema.

\subsubsection{Estrategia complementaria de retrospectiva: Abstracción y retroactividad}

La estrategia para la retrospectiva, es la abstracción en esquemas de los principales momentos históricos de transformación urbana identificados en el trabajo de análisis. El proceso de abstracción que se evidenció en los anteriores esquemas presentados en el gráfico 8, permite entender en síntesis el producto histórico que ha

\footnotetext{
${ }^{3}$ Resaltados con texto rojo en gráfico 5
} 
llevado a la congestión. Los esquemas funcionan como estrategias de diseño que apoyan la transformación de San Victorino, no obstante, estos momentos históricos también han aportado a la generación del problema, y en este último caso, sirven como referentes para evitar su aplicación.

\subsection{Radiografía urbana del estado actual de San Victorino}

En segundo lugar para entender la congestión en San Victorino, se profundiza en su situación actual, en términos físicos y estadísticos, por medio de la aplicación del componente de radiografía, que hace parte de la metodología aplicada. La radiografía se refiere a la caracterización actual y clasificación tipológica de San Victorino. Busca identificar las tipologías y datos urbanos existentes que componen el área de estudio, con el fin de entender su funcionamiento y servir como insumo para su transformación.

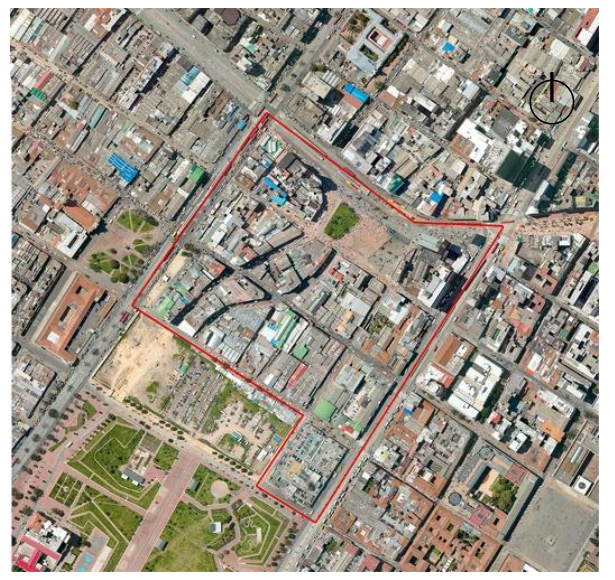

\begin{tabular}{|c|c|c|c|}
\hline \multicolumn{5}{|c|}{ Áreas Generales } \\
\hline Ítem & Unidades & Valor & Notas \\
\hline Área Bruta & ha & 14,6 & Área total \\
\hline Área Privada & ha & 8,9 & $61 \%$ de área total* \\
\hline Área ocupada & ha & 8,0 & $90 \%$ de área privada \\
\hline índice de ocupación & índice & 0,90 & \\
\hline Lotes BIC & $\mathrm{m} 2$ & $8.833,3$ & $10 \%$ de área privada \\
\hline & & & \\
\hline Área Construida & & 230.131 & \\
\hline Índice de Construcción & índice & 2,6 & \\
\hline & & & \\
\hline Manzanas & un & 15 & \\
\hline Lotes & un & 245 & 16 veces no. de Manzanas \\
\hline Predios & un & 3213 & 13 veces no. de Lotes \\
\hline Unidades empresariales & & 5729 & 1,78 veces no. de predios \\
\hline Propietarios & un & 4270 & 1,33 veces no. de predios \\
\hline
\end{tabular}

> 6. Área de Estudio y números catastrales de manzanas. Tomado de orto foto y mapa de referencia de Bogotá, IDECA 2016 > Tabla 2. Áreas Generales de área de estudio. Datos tomados de Mapa de Referencia, IDECA 2015-2016

El cuadro de áreas generales evidencia la alta subdivisión del espacio, que pasa de 15 manzanas, a 245 lotes y 3.213 predios, es decir trece veces el número de lotes en desarrollos de baja altura que mayormente se encuentran entre uno y tres pisos. El tejido urbano de San Victorino presenta alta ocupación del área privada, con el $90 \%$, dispuesto sobre manzanas que originalmente fueron concebidas en base a una modulación de 100 x 100 metros aproximadamente; esto ha generado la marcada subdivisión de los predios, que actualmente son aprovechados con edificaciones de baja altura, en una diversidad formal donde se conservan pocas construcciones de interés cultural. En los 3.213 predios que incluyen los estacionamientos y diversos usos en el polígono de estudio, se encuentran 5.729 unidades empresariales que principalmente se dedican al comercio al por menor y confección de prendas de vestir, sumando 35\% del total de las unidades.

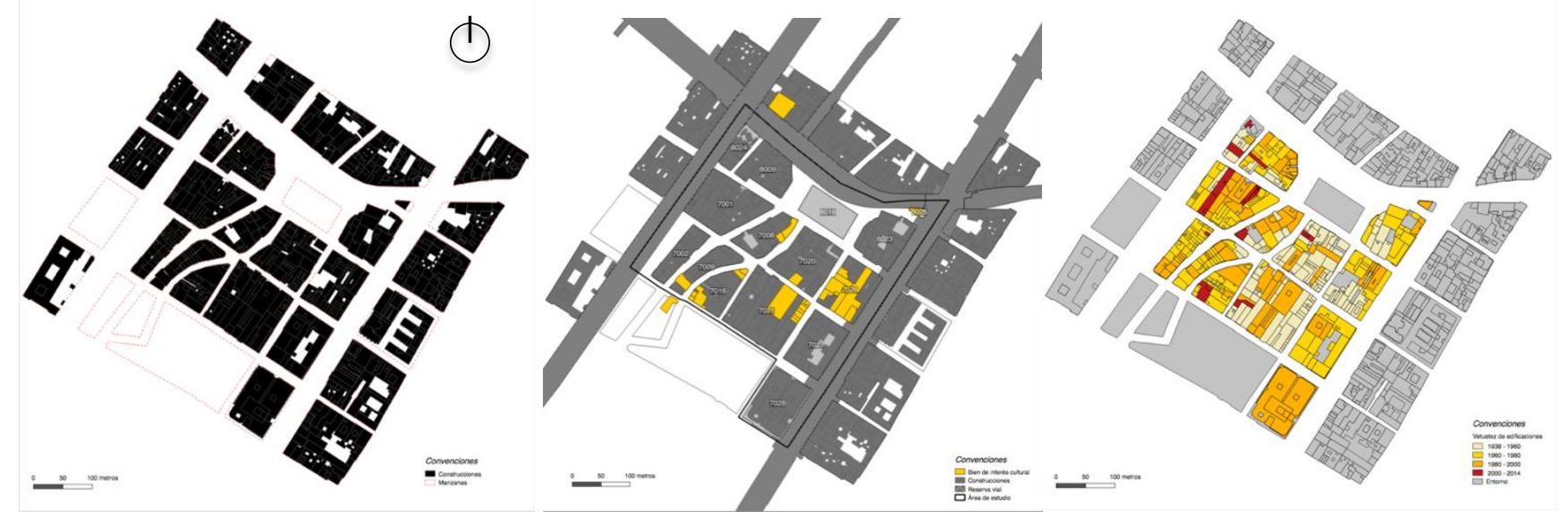

> 7. Tejido urbano, afectaciones y vetustez del área de estudio. Elaborado con información de Mapa de Referencia, IDECA 2015-2016 
El 66\% del área construida en San Victorino corresponde al uso de comercio en corredor comercial, depósitos de almacenamiento y oficinas en menor cantidad. Esta cifra demuestra el carácter comercial de San Victorino y su dinámica con las oficinas y un almacenamiento representativo. La mayor parte de las construcciones de San Victorino fueron edificadas en los últimos 70 años, con tipologías diversas que han sufrido adaptaciones forzosas a través del tiempo, dando la impresión de variedad y dificultad en la lectura del espacio urbano; no obstante, por su potencial comercial, San Victorino presenta algunos de los valores de suelo mas altos de la ciudad.

La población residente en San Victorino ha tenido una tendencia a la baja, en el censo de $2005^{4}$ se identificaron 200 habitantes, y en la proyección de población de $2011^{5}$ se calcularon 86 habitantes. La cantidad de empleos identificada en la zona, en 2005 fue de 8.267, con una tendencia al alta. en "una estimación preliminar se indica que la actividad económica comercial de San Victorino generaba 20.798 empleos en 2007"6, sin contar la presencia de la informalidad en el sector.

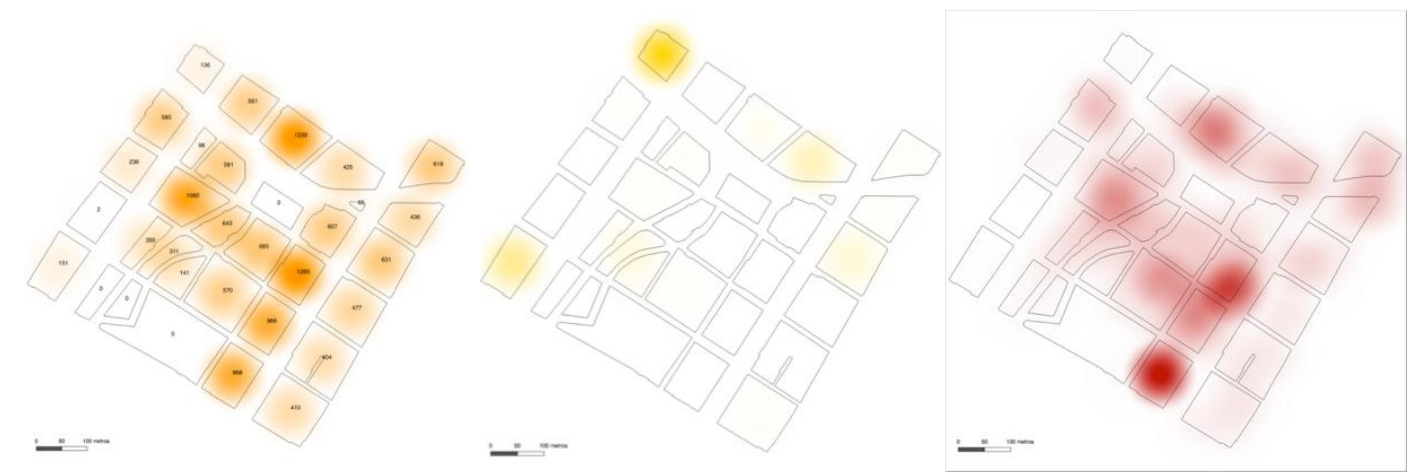

> 8. Concentración de empleos por manzana, Elaborado con información de censo DANE, 2005

> 9. Concentración de Población. Elaborado con información de proyección SDP-DANE, 2011

> 10. Concentración de Unidades empresariales. Elaborado con base Cámara de Comercio, 2015

San Victorino es uno de los sectores mejor comunicados de Bogotá con transporte masivo. En un radio de 800 metros (distancia caminable) se encuentran 5 estaciones de Transmilenio (BRT), y se proyecta una estación de Metro. En un día de julio, la estación del sistema Transmilenio de la Avenida Jiménez, recibe 44.892 entradas. ${ }^{7}$

La recolección de datos presentada en esta sección de radiografía permitió identificar el volumen de actividades y áreas que actualmente funcionan en San Victorino, sirviendo como información de insumo para la etapa de transformación.

\subsubsection{Estrategia complementaria de Radiografía:}

El proceso de análisis de Radiografía permitió cuantificar e identificar las áreas y actividades que se presentan actualmente en San Victorino.

La estrategia para el proceso de Radiografía, se enfocó hacia la optimización del programa urbano de San Victorino para disminuir la congestión, y a la búsqueda de factibilidad económica para la gestión de su transformación. Se tomaron como referencia las áreas construidas existentes por actividad.

Adicional al ejercicio de actividades se retomaron tipologías relevantes para escenarios que permitan evaluar comparativamente los beneficios de cada una en el sistema espacial y programático del área de estudio. En el

\footnotetext{
${ }^{4}$ Fuente: DANE

${ }^{5}$ Fuente: DANE, SDP

6 "Parte II: actualización y ajuste del censo socio-económico de San Victorino". Informe Final. Contrato ERU No. 007 de 2007. Centro

Nacional de Consultoría, Economía Urbana, Empresa de Renovación Urbana. Bogotá, julio de 2007.

${ }^{7}$ Datos de Transmilenio S.A. 2015
} 
siguiente gráfico se presentan los principales criterios abstraídos de las tipologías identificadas como instrumentos transformadores de congestión, que son insumo para el proceso transformación de San Victorino.

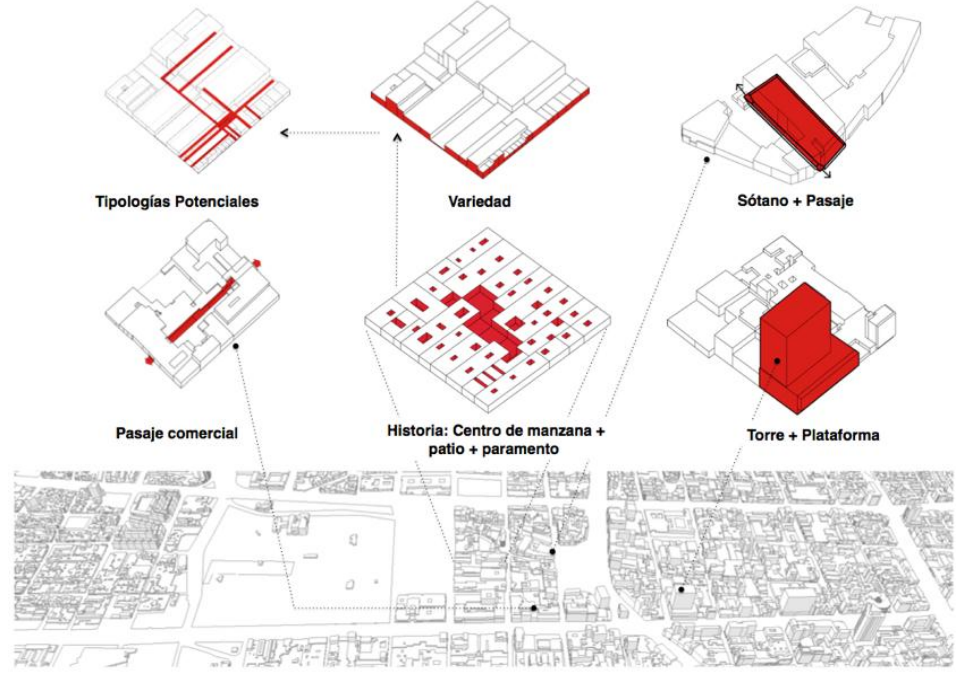

> 11. Características extraídas de las tipologías actuales. Elaboración propia

Entender y calcular las actividades del territorio, y la forma como estas ocurren en el espacio o en la tipologías existentes, permite estratégicamente disminuir el salto que se puede generar, entre lo que es hoy San Victorino y la formulación de escenarios de lo que podrá ser. En términos de volumen, este insumo permite analizar y redistribuir mejor la actividades, disminuyendo el riesgo de que se genere de nuevo la congestión.

\subsection{Configuración espacial de San Victorino}

En tercer lugar y como componente principal de la metodología construida para entender la congestión, se analiza la configuración espacial de San Victorino, que se refiere a la forma como está organizado el espacio de la ciudad, y a su relación con la sociedad.

Como principal teoría y metodología para evaluar dicha configuración y concentración humana, se hace uso de "Space Syntax" donde los espacios son entendidos como vacíos (calles, plazas, cuartos, parques, etc.). Los vacíos están definidos por obstrucciones o construcciones que pueden restringir el acceso o la visión. Las ciudades son agregados de edificios que se mantienen unidos por esta red de espacios o vacíos. La red conecta una serie de espacios de calles que forman juntos una estructura. La estructura es el resultado óptimo de los caminos más cortos desde todos los orígenes hacia todas las destinaciones en el sistema espacial que es el que agrupa todo. Esta estructura tiene una arquitectura y por esta, nosotros encontramos cierta geometría y cierta topología, que es, un cierto patrón de conexiones.

El análisis y la representación del espacio, se realiza a partir de mapas axiales y de segmentos, que son representaciones sintácticas y medibles del espacio, que reflejan propiedades estructurales de la trama urbana. Los segmentos se identifican como calles y se analizan con el resultado de la medición topológica, métrica, y de conexiones angulares; a diferentes radios de distancia de análisis.

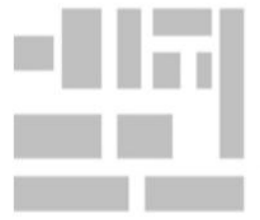

a.

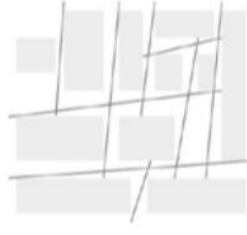

Axial lines

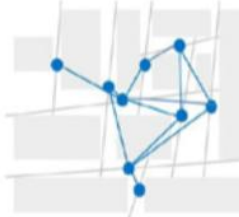

Axial lines - Axial graph
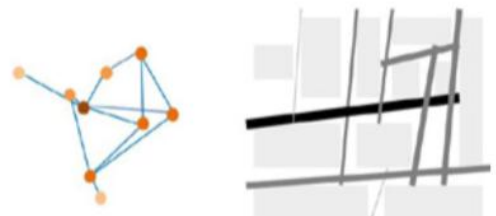

Higher connectivity d. e. 
> 12. Ejemplo representación axial. Tomado de libro Space is the Machine, Bill Hillier, Pág. 72

Usando este tipo de representación es posible calcular integración y elección, para medir características espaciales como la accesibilidad y comparar propiedades formales de configuración espacial que pueden inducir a la concentración y a la congestión. La integración y elección, se traducen consecutivamente en: hacia donde nos movemos y por dónde nos movemos, permitiendo predecir los movimientos y la acumulación en el espacio.

La medida de integración ${ }^{8}$ de Hillier, es igual a la cantidad de nodos de intersección por cantidad de nodos de intersección, dividido la profundidad total. (Integración $\left.=\left(N^{*} N C\right) / T D\right)$. La medida de elección se calcula en base a todos los pares de posibles orígenes y destinos, dando prioridad a las rutas más cortas entre uno y otro. Los cálculos se generan a partir de las medidas por medio de la profundidad angular de los segmentos. La profundidad en el análisis espacial de San Victorino se genera a partir del método "Tulip" que esta configurado para aproximar los cambios de ángulo de los segmentos.

A continuación se presenta el análisis de segmentos aplicado al área de estudio en relación a la escala de toda la ciudad con las medidas de integración y elección, permitiendo diagnosticar y predecir en donde se generan las acumulaciones.

La aplicación del análisis de segmentos a toda la estructura espacial de Bogotá, en radios de 10.000 metros revela un alto nivel de integración en el área del centro histórico de la ciudad y en torno a las vías arterias principales que actualmente componen la ciudad. En el análisis, San Victorino se ubica en parte de los segmentos más integrados de la ciudad (en rojo), comprobando la eficacia de la medición en relación a la predicción de hacia donde va la gente y donde puede generarse tal acumulación que hoy se vive en San Victorino. Con el mismo criterio se hizo el análisis con la medición de elección, el resultado demuestra que los segmentos mayormente elegibles coinciden con la estructura vial principal de la ciudad. El sector de San Victorino es bordeado por cuatro de las arterias principales de la ciudad, que el análisis evidencia con el rango máximo de elegibilidad.

El resultado del análisis comprueba la relevancia de la configuración espacial en relación a la congestión, debido a que en el radio de análisis de 10.000 metros, la posición de San Victorino se encuentra en medio de las arterias que mayor cantidad de usuarios elegirían conduciendo medios motorizados de movilidad; argumentando así la intensidad de llegada y salida de grandes masas en el sector.

\footnotetext{
${ }^{8}$ Hacia donde nos movemos
} 


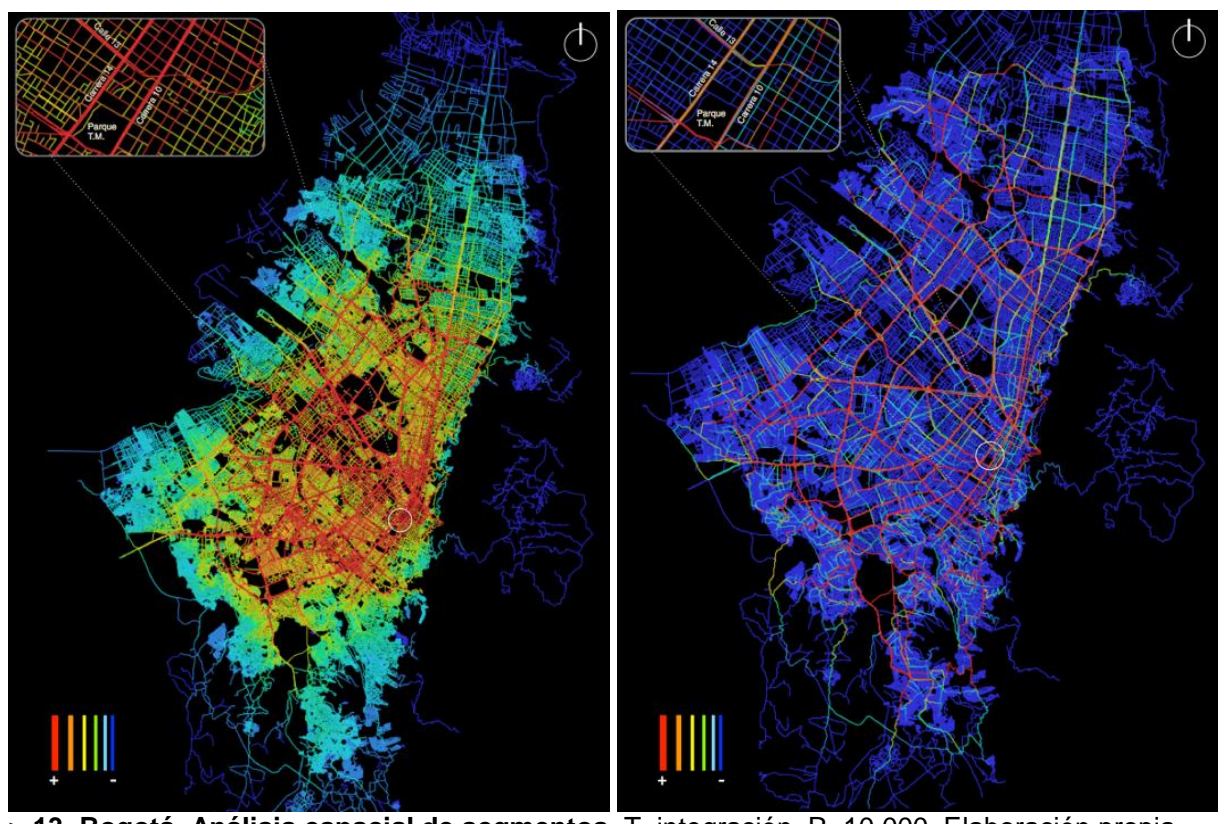

> 13. Bogotá. Análisis espacial de segmentos, T. integración, R. 10.000. Elaboración propia

$>$ 14. Bogotá. Análisis espacial de segmentos, T. elección, R. 10.000. Elaboración propia

Posteriormente se realizó el mismo análisis en un radio de 800 metros a toda la ciudad, el resultado para las medidas de elección e integración fue similar, debido a que las áreas más integradas en este radio se identifican ubicadas al borde sur de la ciudad y algunas zonas centrales al oriente, como la calle 26 con séptima.
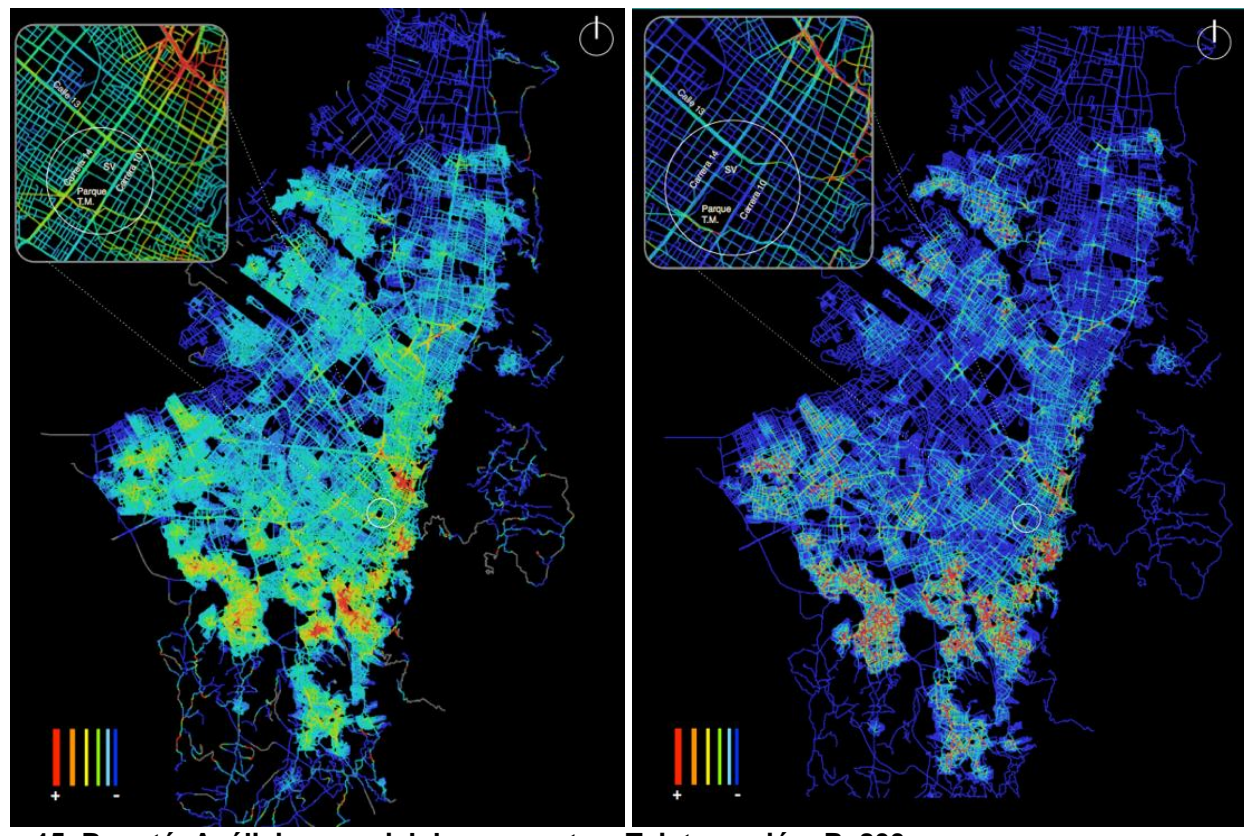

$>$ 15. Bogotá. Análisis espacial de segmentos, T. integración, R. 800.

> 16. Bogotá. Análisis espacial de segmentos, T. Elección, R. 800. Elaboración propia

A diferencia del análisis de 10.000 metros, en la distancia caminable de 800 metros, San Victorino se acerca más a un rango de área disgregada, que sugiere que la gente llegaría a San Victorino mayormente por medios motorizados que por medios de baja velocidad. Por otro lado se interpreta que a nivel peatonal San Victorino se encuentra disgregado de su entorno inmediato, coincidiendo con el hecho identificado en la retrospectiva, de Istla entre Avenidass. 
En relación al resultado de las dos medidas de análisis aplicadas a Bogotá, se argumenta que la congestión urbana en San Victorino, se ha formado debido a la configuración espacial general de la ciudad, en correspondencia a la consideración que hace Bill Hillier, con respecto a que la estructura espacial de la ciudad funciona como un todo, así una modificación a esta, representa cambios que influyen ámbitos espaciales mayores al lugar de intervención y viceversa.

Lo anterior direcciona a predecir que la solución inmediata a la congestión, a partir de la configuración espacial, supera una modificación sectorial de la estructura de la ciudad, es decir una modificación a la forma urbana específicamente de San Victorino. No obstante, en base a la misma idea, una modificación parcial de la configuración espacial, puede influenciar gradualmente en el tiempo un ámbito mayor de la estructura general; y así mismo puede disminuir el impacto global del problema.

En esta perspectiva de menor escala, se decide aplicar el análisis a una escala caminable del sector de San Victorino en un radio de 1.000 metros, con el objetivo de abordar el problema de manera inductiva y de acuerdo a posibilidades factibles que se alejan de la modificación general de la estructura de la ciudad.

Para el análisis en un radio de 1.000 metros, se optimizó el mapa axial base al modo de movilidad peatonal, incluyendo la continuidad e intermitencia de pasos peatonales. Por ejemplo en las vías arterias se restringió el paso en sectores donde no existe cebra, semáforos o puentes que permiten el paso adecuado de peatones.
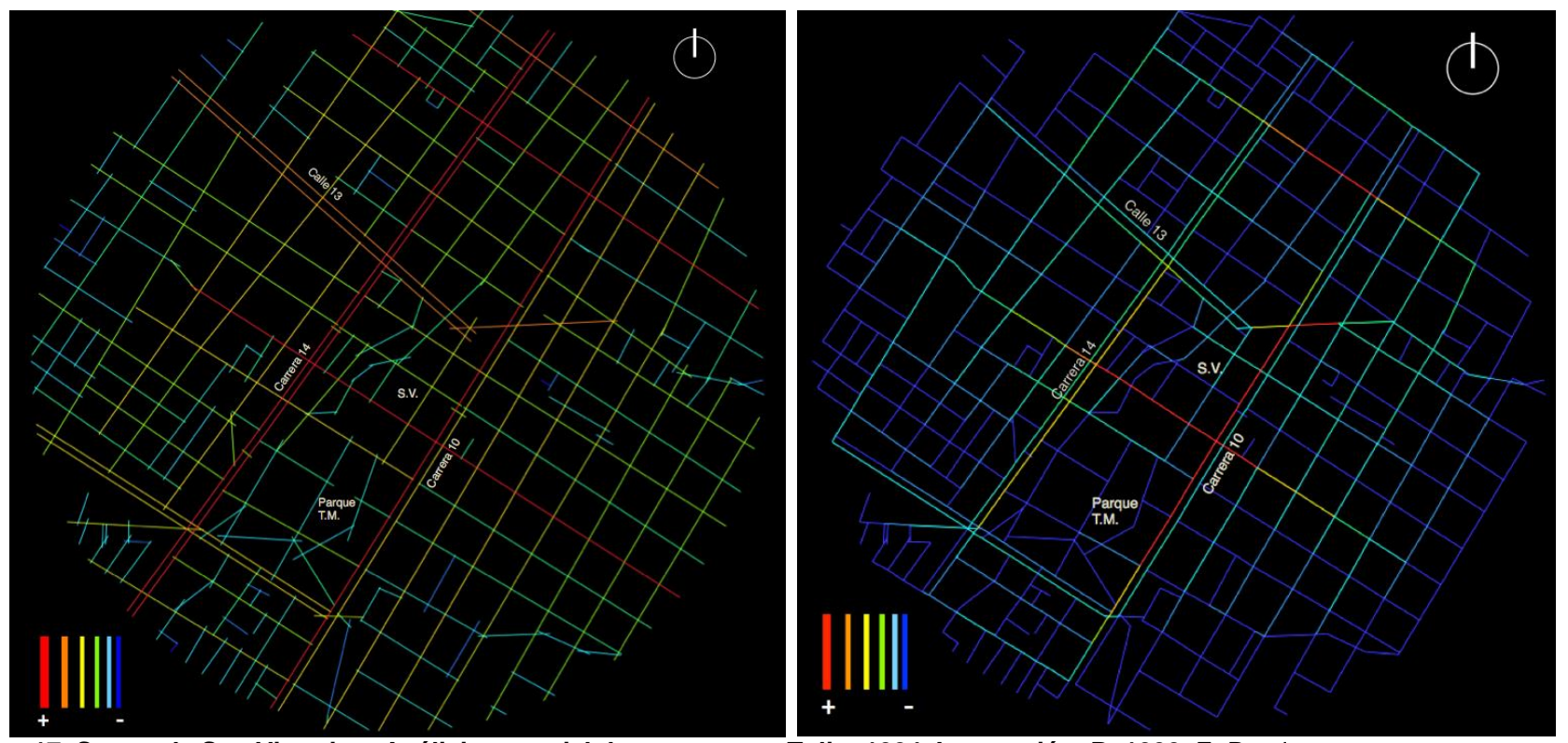

$>$ 17. Sector de San Victorino. Análisis espacial de segmentos, Tulip, 1024. Integración, R. 1000. E. Propia

$>$ 18. Sector de San Victorino. Análisis espacial de segmentos, Tulip, 1024. Elección, R. 1000. E. Propia

Los segmentos más integrados y elegibles en un radio de 1.000 metros, reiteraron la importancia de las vías arterias: calle 13, carrera 14 y carrera 10, que conectan actualmente a San Victorino con toda la ciudad. Adicionalmente aparece resaltada la calle 10 , que es una vía de carácter local que ha conectado transversalmente el centro de la ciudad en sentido oriente - occidente. Actualmente en el POZ centro ${ }^{9}$, esta vía se considera de carácter estructural en la conexión peatonal del centro de la ciudad junto con la calle 11, conectando una serie de plazas que aparecieron en la historia del crecimiento del centro de la ciudad desde la colonia.

\footnotetext{
${ }^{9}$ El Plan de ordenamiento Zonal Centro es un instrumento de planeación que tiene Bogotá para organizar urbanísticamente el centro de la ciudad
} 
También, se encontró que San Victorino está inmerso en una estructura espacial equilibrada, que cuenta con buena accesibilidad por sus bordes, que corresponden a las vías vehiculares más importantes de la ciudad. No obstante, la interconexión de vías locales con espacios alternos como la Plaza España, que pueden equilibrar la intensa acumulación de San Victorino, es débil, por la difícil conectividad peatonal que presenta ruptura en los ejes principales o vías arterias.

\subsubsection{Estrategias de configuración espacial}

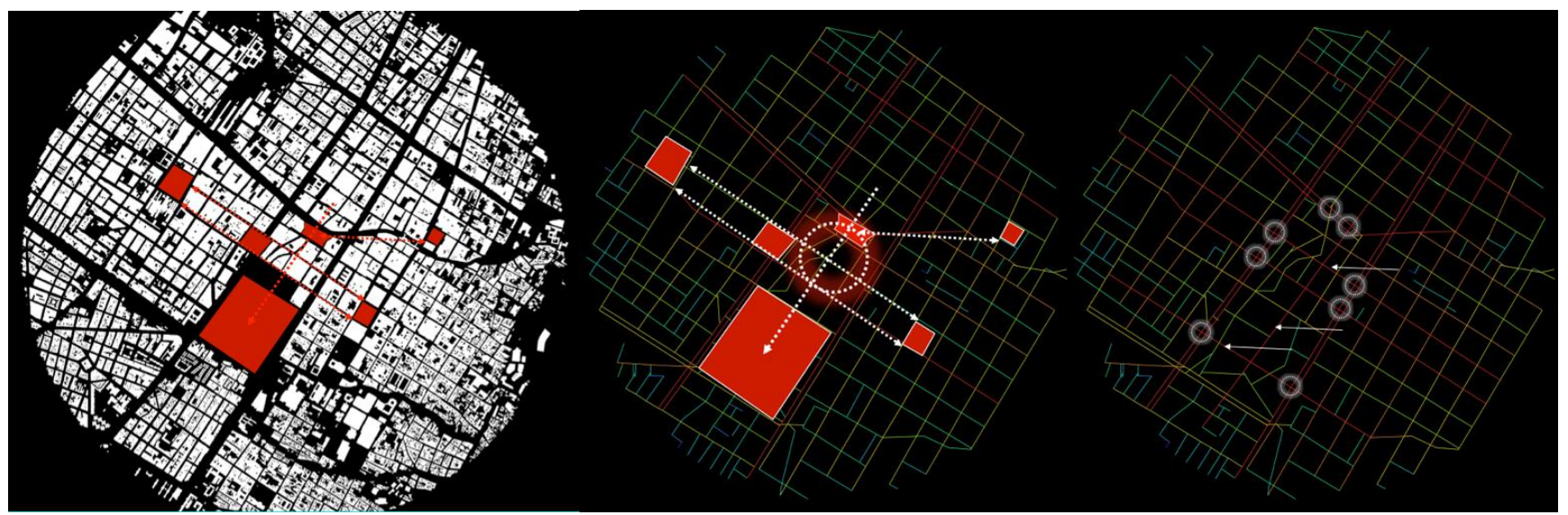

> 19. Espacios y tensiones potenciales a conectar en el centro de Bogotá. Elaboración propia

Como resultado del análisis realizado a nivel peatonal con Space Syntax, con base en la baja conexión que se presenta peatonalmente en la estructura espacial local, se busca descongestionar orientando a la gente hacia espacios públicos abiertos, simbólicos y de vocación comercial en el espacio urbano, por medio de la reconfiguración de la trama y tejido urbano, equilibrando la ocupación del espacio.

Las estrategias de configuración espacial buscan inducir la forma urbana a transformaciones, que aporten a solucionar gradualmente el problema de la congestión en San Victorino, y a nivel global de la estructura general de la ciudad. A continuación se enuncian y describen las estrategias de configuración urbana:

\section{- Estrategia 1. Conectar - Integrar}

Se refiere a rescatar la conectividad interrumpida por fragmentos de la estructura espacial de la ciudad, que impiden la fluidez y funcionan como actores negativos en la movilidad inmediata del sector.
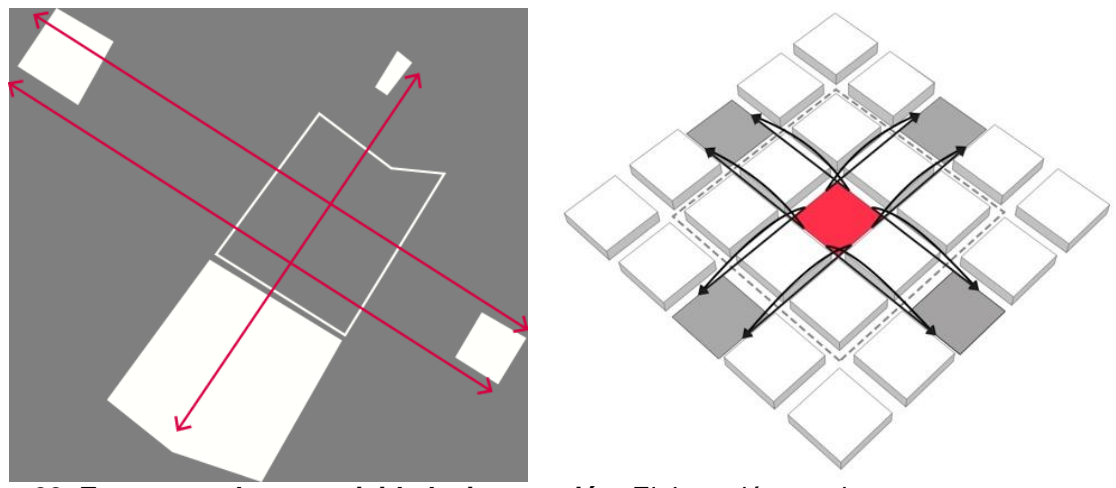

$>$ 20. Esquemas de conectividad e integración. Elaboración propia

- Estrategia 2. Fluidez - Equilibrar 
La fluidez se identifica como la cualidad que permite a través de la configuración espacial disminuir el efecto de acumulación o llenado del espacio, equilibrando la ocupación, y tensionando los recorridos hacia áreas receptoras suficientes para albergar los programas requeridos.
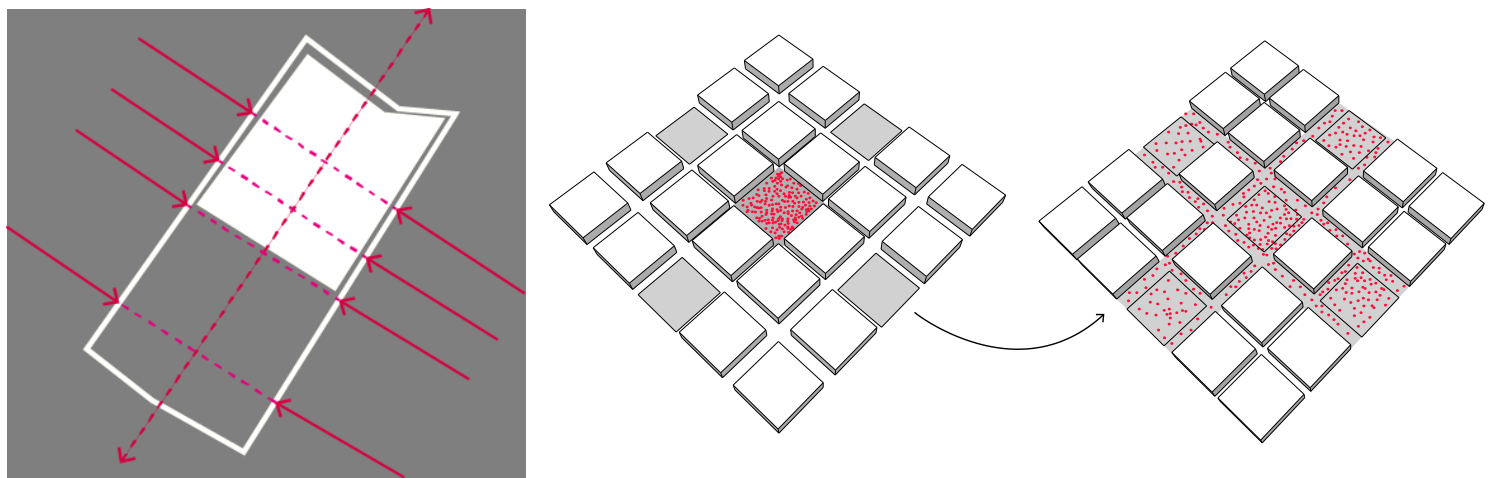

> 21. Esquemas de Fluidez. Elaboración propia

\section{- Estrategia 3. Desocupar}

Se refiere a responder a la presión generada por las masas en el espacio, desocupando la superficie, y compensando el volumen en altura. La estrategia de desocupar se aborda en dos sentidos, que se aplican independientemente en los escenarios de transformación. El primero de estos es la retroactividad del carácter histórico de desocupar el centro de manzana, y el segundo desocupando de manera equilibrada con construcción subterránea y en altura, en algunos casos sobre plataformas.
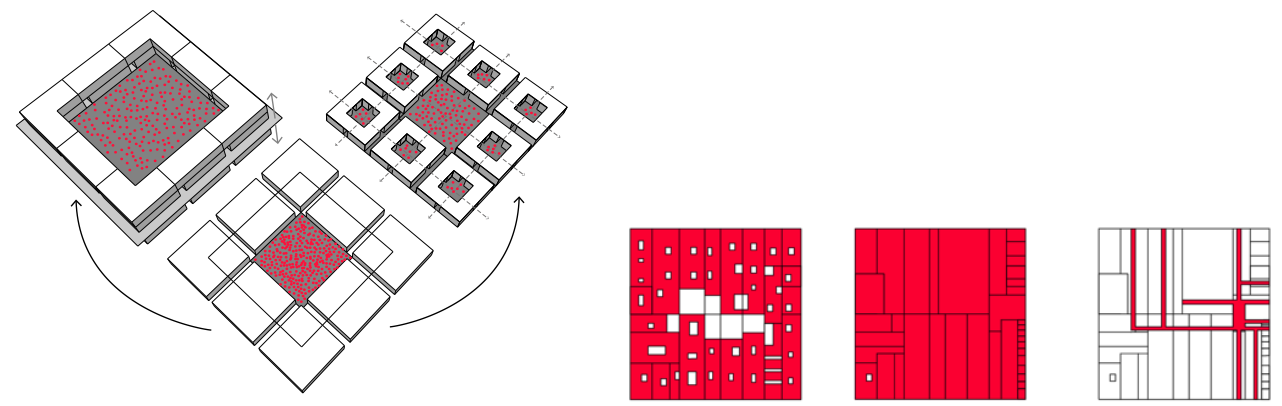

> 22. Esquemas de desocupación del espacio. Elaboración Propia

\section{- Estrategia 4. Flexibilidad - Optimizar}

Se refiere a la cualidad que tiene el espacio para permitir diversas actividades en el tiempo, respondiendo de manera óptima a la variedad de programas que se pueden presentar en el espacio de la ciudad.
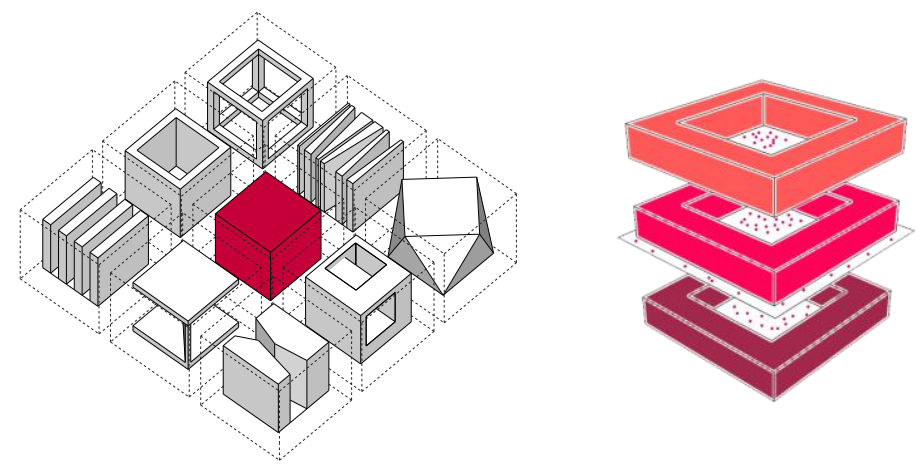
Las anteriores estrategias de configuración espacial se aplicaron a escenarios de transformación en San Victorino, tal y como se muestra en la siguiente sección de diseño de escenarios. La aplicación de las estrategias se realizó para disminuir la acumulación de masa que actualmente presenta el sector y que ha llevado a la congestión.

\section{DISEÑO Y TRANSFORMACIÓN DE SAN VICTORINO}

Con el fin de evaluar la transformación de la congestión en San Victorino, con el fundamento de las estrategias anteriormente descritas se propone el diseño de cinco escenarios aplicados de diferentes formas y grados de ocupación. A continuación se presentan y describen brevemente cada uno de los escenarios:

\section{- Escenario 1. Memoria}

El escenario Memoria se adapta a las condiciones patrimoniales e históricas del área de estudio, conservando los bienes de interés cultural y planes de implantación aprobados para nuevos proyectos. El nuevo tejido propuesto retoma la tipología de construcción paramentada a la manzana en relación a los bienes de interés cultural existentes; el tratamiento a los centros de manzana se configura por medio de porosidades, que se convierten en patios que recuerdan las antiguas tipologías coloniales: atravesando la estructura de patios de centros de manzana propuestos, se incluyen circulaciones alternas por medio de pasajes que interconectan el sistema a escala del peatón.

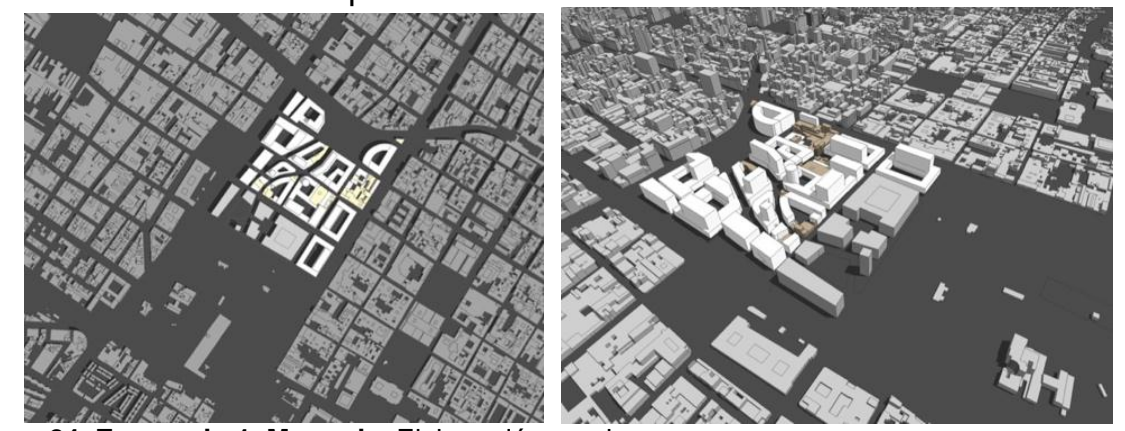

> 24. Escenario 1. Memoria. Elaboración propia

\section{- Escenario 2. Contextualización}

Este escenario conserva algunas de las características tipológicas aplicadas al escenario 1, como el paramento y la habilitación de los centros de manzana. Adicionalmente se reduce la ocupación de la superficie, simplificando y aumentando los espacios libres de centro de manzana. Al tejido descrito, se incluyen elementos de torre y plataformas que paramentan con aleros los espacios exteriores y permiten el uso público de la dimensión espacial superior, generando así la tipología aplicada. También se proyectaron edificios en el borde del parque Tercer Milenio, con los cuales se busca activar el espacio y articular a San Victorino con su entorno inmediato. Así mismo se incluyeron espacios en el subsuelo con conexiones subterráneas peatonales, en el eje de las calle 10 y 11 para conectar con las plazas alternas. 

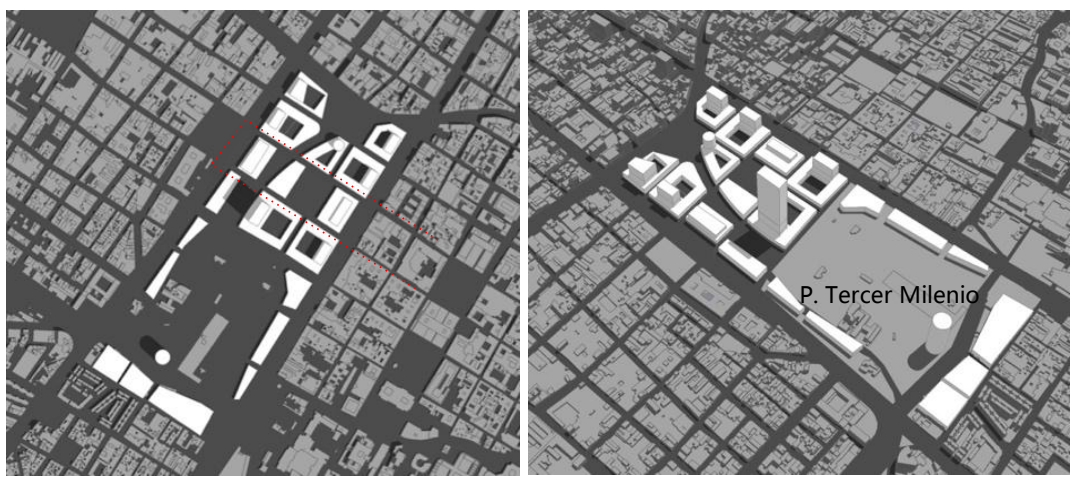

$>$ 25. Escenario 2. Contextualización. Elaboración propia

\section{- Escenario 3. Concepto}

Se propone una "megaestructura" compacta que realza y sintetiza la plaza en un espacio central abierto, que busca disminuir la acumulación y la congestión sin perder la actividad. Adicionalmente se enmarca el Parque Tercer Mileno con un edificio continuo perimetral. La conectividad con el entorno se da por medio de brazos subterráneos y elevados que atraviesan.

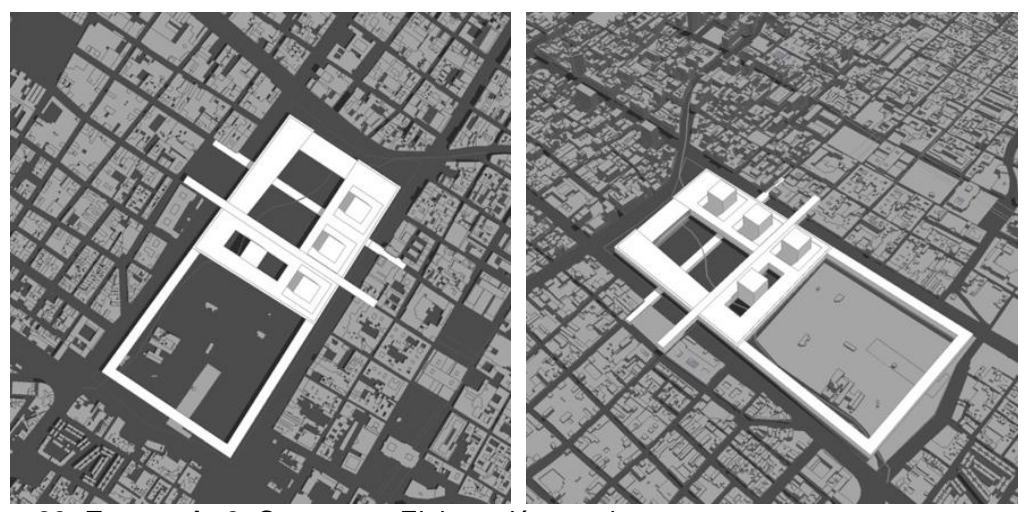

> 26. Escenario 3. Concepto. Elaboración propia

\section{- Escenario 4. Mercado}

Este escenario surge de forma inductiva, a partir de la lógica de configuración a la que se ha adaptado San Victorino actualmente, que es lograr la mayor cantidad de frentes de fachada para optimizar el espacio en relación a las ventas. En este marco, se elabora una tipología base de módulos de venta organizados bajo una cubierta de servicios, alrededor de espacios centrales que se conectan por corredores comerciales continuos, y repetitivos con accesos a cortas distancias. Al igual que en el Escenario 2, se proyecta la conexión peatonal subterránea, en el eje de las calle 10 y 11 para conectar con las plazas alternas.
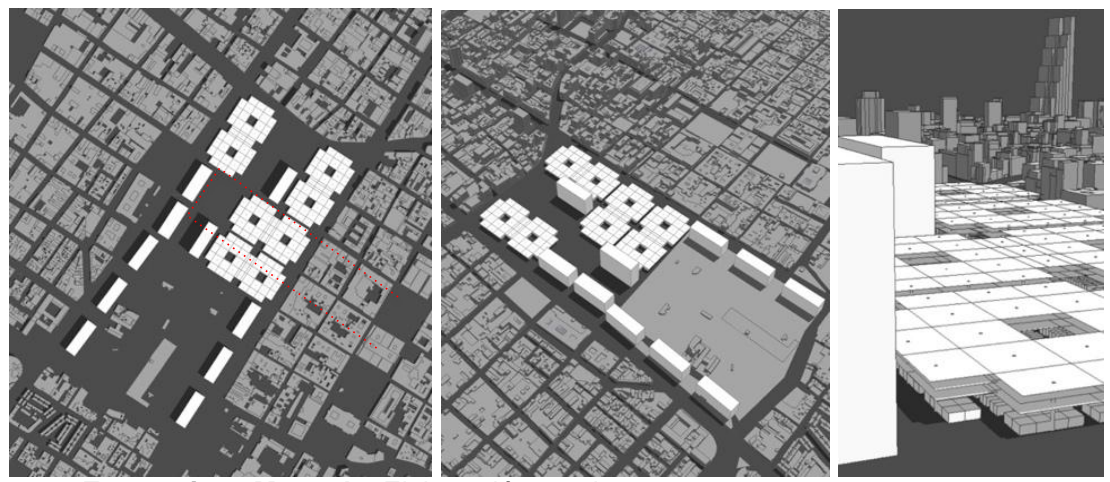

> 27. Escenario 4. Mercado. Elaboración propia 


\section{- Escenario 5. Síntesis}

Este escenario busca con el mínimo de elementos, lograr aplicar las estrategias de configuración urbana de manera óptima. La síntesis consiste en una torre y una plataforma. Se propone el soterramiento de las vías arterias para conectar en superficie peatonalmente por medio de la plataforma el centro oriental y occidental. El funcionamiento se resume en la zonificación de medios de movilidad en capas sobrepuestas en orden vertical. En los niveles subterráneos se soluciona la movilidad motorizada, y la logística de los productos que llegan a San Victorino; en la superficie, se amplia un espacio flexible para diversas actividades humanas; y en los pisos superiores se organizan las actividades de comercio y servicios que actualmente funcionan en el sector. También se proyectó un edificio continuo elevado que integra y desconcentra la actividad hacia el parque.

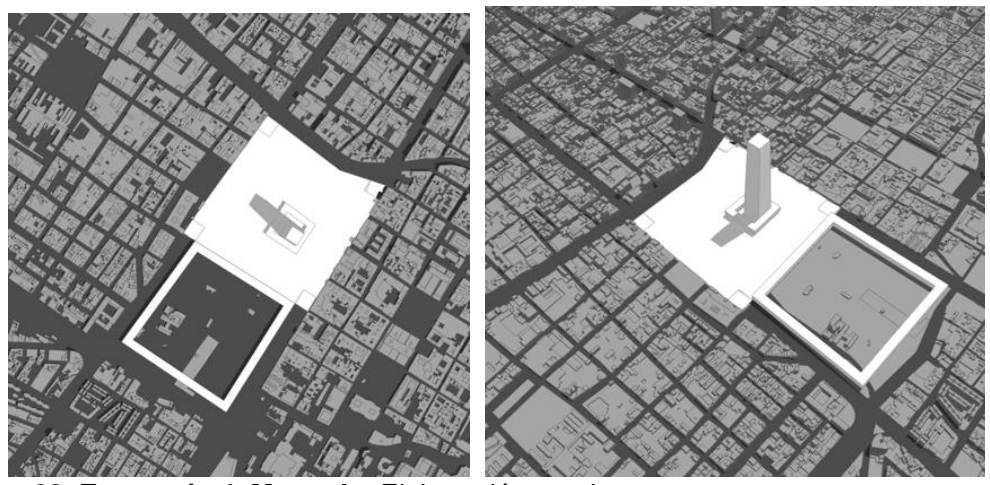

> 28. Escenario 4. Mercado. Elaboración propia

\subsection{Evaluación}

Cada uno de los escenarios de diseño presentados anteriormente fueron enfocados a solucionar parcial y gradualmente el problema de la congestión en el espacio urbano, con base en las estrategias planteadas. Con el fin de establecer una priorización que permita evidenciar potenciales y debilidades de cada uno de los escenarios, se evaluaron en torno a los tres mismos temas de Retrospectiva, Radiografía, y Configuración Espacial, que permitieron entender el problema y construir las estrategias de diseño. A continuación se presenta cada una de las evaluaciones y su ponderación final:

\subsubsection{Evaluación de retrospectiva}

Para la evaluación de retrospectiva se calculó la cantidad de esquemas de momentos históricos relacionados a cada escenario, que aportan a la transformación de la congestión y a la memoria del lugar. Adicionalmente a los momentos históricos seleccionados, se sumaron los criterios encontrados en las tipologías estudiadas en la retrospectiva y en la radiografía, como unidades adicionales para la calificación.

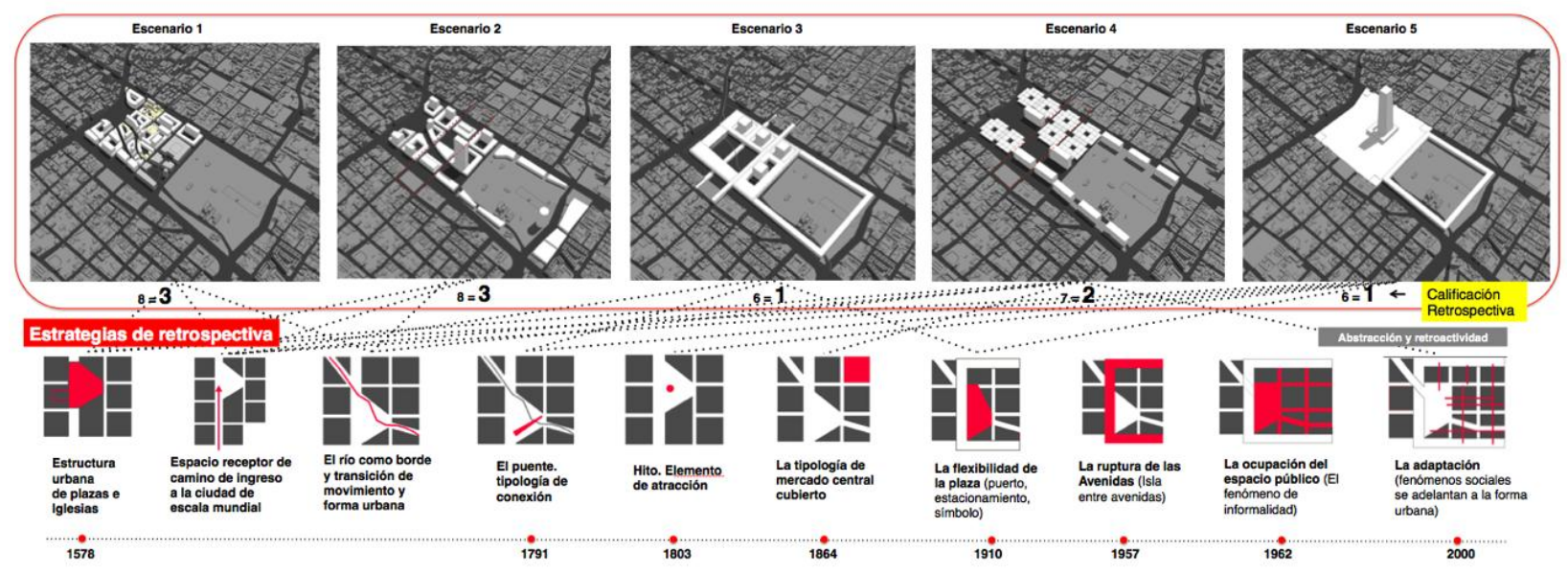


>29. Calificación de esquema de Retrospectiva. Elaboración propia

La calificación se dio en tres rangos, de acuerdo a la cantidad de momentos y tipologías históricas que se relacionaron a cada uno de los escenarios propuestos.

La mayor calificación la obtuvieron los escenarios 1 y 2, memoria y contextualización, seguidos por los escenarios 4, 3 y 6 respectivamente. Evidenciando la dificultad que se genera en la relación, entre la retroactividad de elementos y el proceso de síntesis y abstracción, que fue realizado gradualmente en el diseño hasta llegar al escenario 5, que obtuvo la menor calificación en retrospectiva.

\subsubsection{Evaluación de radiografía}

Para la evaluación de radiografía, se realizó un esquema de factibilidad económica a cada uno de los escenarios con las áreas de actividad sugeridas en la estrategia. Los valores de suelo y de costos directos son una aproximación que toma como base principalmente datos del Plan Parcial actualmente en curso para el área. En los casos donde se incluyó un área de intervención adicional se tomaron los costos comerciales de suelo. En la tabla 3 se presenta el ejercicio de factibilidad para los cinco escenarios.

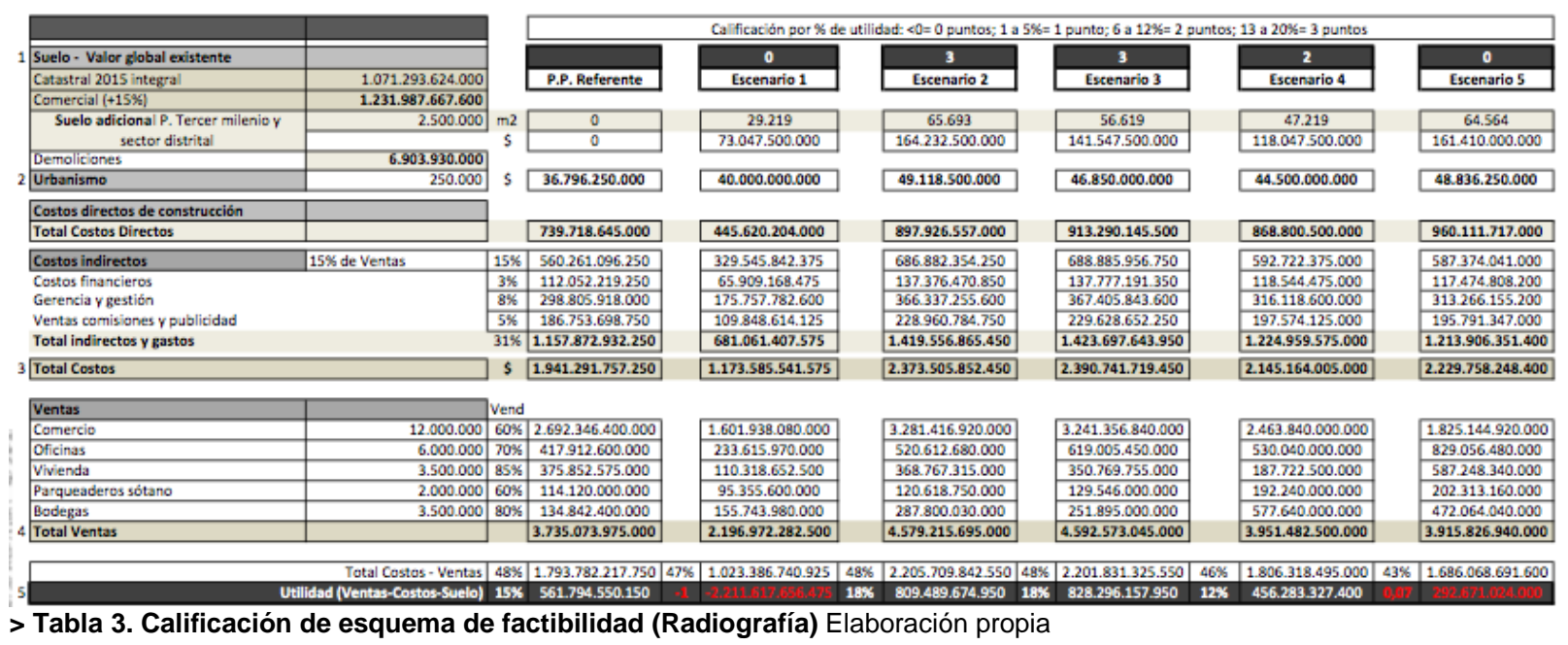

La evaluación de la factibilidad, se calificó en 4 rangos, de acuerdo al porcentaje aproximado de utilidad que resultó de cada uno de los escenarios. Los rangos se calificaron en el siguiente orden: igual o menor a $0 \%$, igual a 0 puntos; de 1 a $5 \%$, igual a 1 punto; de 6 a 12\%, igual a 2 puntos; igual o mayor $13 \%$, igual a 3 Puntos.

La mayor calificación la obtuvieron el escenario 2 y el escenario 3, que con su forma urbana, permitieron ubicarse entre los escenarios con mayor área construida total y de uso comercial; este último se menciona debido a que el escenario 5 obtuvo un porcentaje negativo de utilidad, mientras su área construida figuró en el rango de los escenarios con mayor calificación, arriba de $500.000 \mathrm{~m} 2$, sin embargo, el área construida de comercio fue la más baja. Lo anterior demuestra la importancia de la relación entre la actividad y la forma urbana.

\subsubsection{Evaluación de configuración espacial}

La evaluación de configuración espacial se selecciona como principal, y se le da mayor relevancia en la ponderación final, debido a que se enfoca directamente al estudio del espacio y su relación con la solución al problema de la congestión.

Los gráficos siguientes permiten leer las concentraciones y la conectividad de San Victorino, por medio de análisis de segmentos, con medidas de elección e integración. Los gráficos se organizan (de arriba a abajo) en: ubicación, grafico de relación integración - elección, análisis de integración y análisis de elección. En el gráfico de puntos en coordenadas $X, Y$; se traza un línea blanca que representa el eje de equilibrio, permitiendo revelar 
la distribución del movimiento en la estructura de segmentos, y por lo tanto la concentración de las masas. La distribución organizada de puntos o segmentos que más se acerca equilibradamente al eje, representa un mayor grado de descongestión y por lo tanto una mayor calificación.
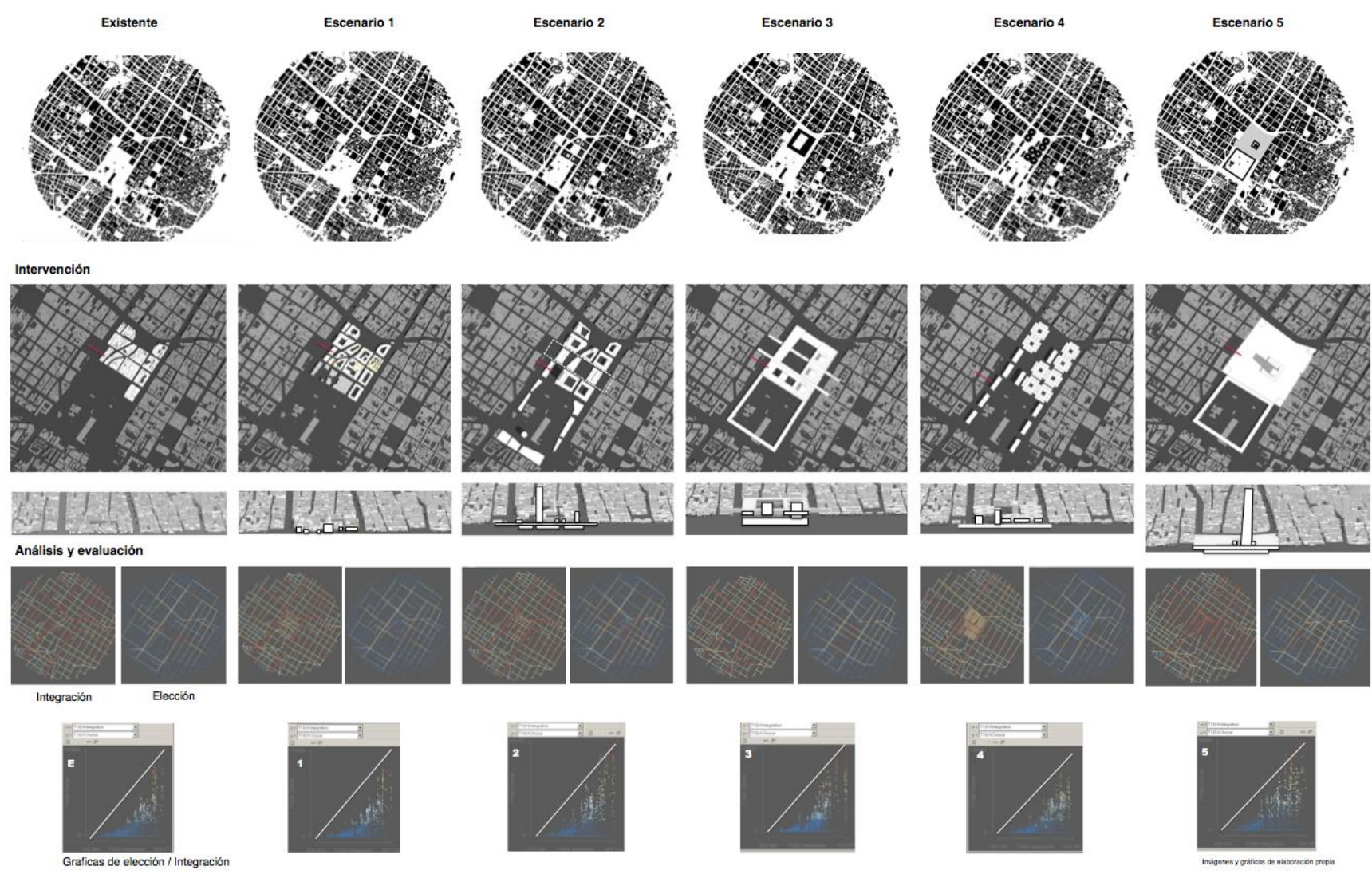

Puntuación de acuerdo a rango de integración
y elección cercano a la medida de equilibrio.

1

3

2

2

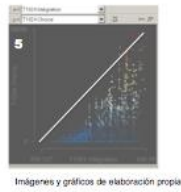

3

> 30. Calificación de análisis de configuración espacial. Elaboración propia

La calificación de los escenarios se realiza con el cruce de variables de integración y elección, dando mayor puntaje a las alternativas que se acerquen con sus segmentos a la línea media que representa el equilibrio de la configuración espacial, induciendo a descongestionar el área hacia espacios alternos de igual relevancia.

Los resultados con mayor calificación fueron para los escenarios 2 y 5 , debido a un mayor equilibrio en la distribución de los segmentos en las medidas de integración y elección, en la estructura espacial local. El equilibrio de la estructura permite distribuir mejor las masas, descongestionando el espacio.

\subsection{Resultado de evaluación general}

La calificación final se ponderó dando mayor porcentaje (50\%) a la evaluación de configuración espacial, por ser el eje transversal del trabajo para entender y transformar la congestión, a la evaluación de los dos componentes restantes se les ponderó sobre el $25 \%$.

\begin{tabular}{|l|c|c|c|c|c|c|}
\cline { 2 - 7 } \multicolumn{1}{c|}{} & Escenario 1 & Escenario 2 & Escenario 3 & Escenario 4 & Escenario 5 & Incidencia \\
\hline Configuración espacial & 1 & 3 & 2 & 2 & 3 & $50 \%$ \\
\hline Retrospectiva & 3 & 3 & 1 & 2 & 1 & $25 \%$ \\
\hline Radiografía & 0 & 3 & 3 & 2 & 0 & $25 \%$ \\
\hline Resultado & 1,25 & 3 & 2 & 2 & 1,75 & \\
\hline
\end{tabular}

> Tabla 4. Resultado de calificación general. Elaboración propia 
El resultado mayor es para el escenario 2, sin embargo es relevante leer de manera independiente el resultado de la configuración espacial, donde el escenario 2 y 5 se encuentran con la mayor calificación. En consecuencia como imagen final se avanzó en el detalle de los dos escenarios mencionados.
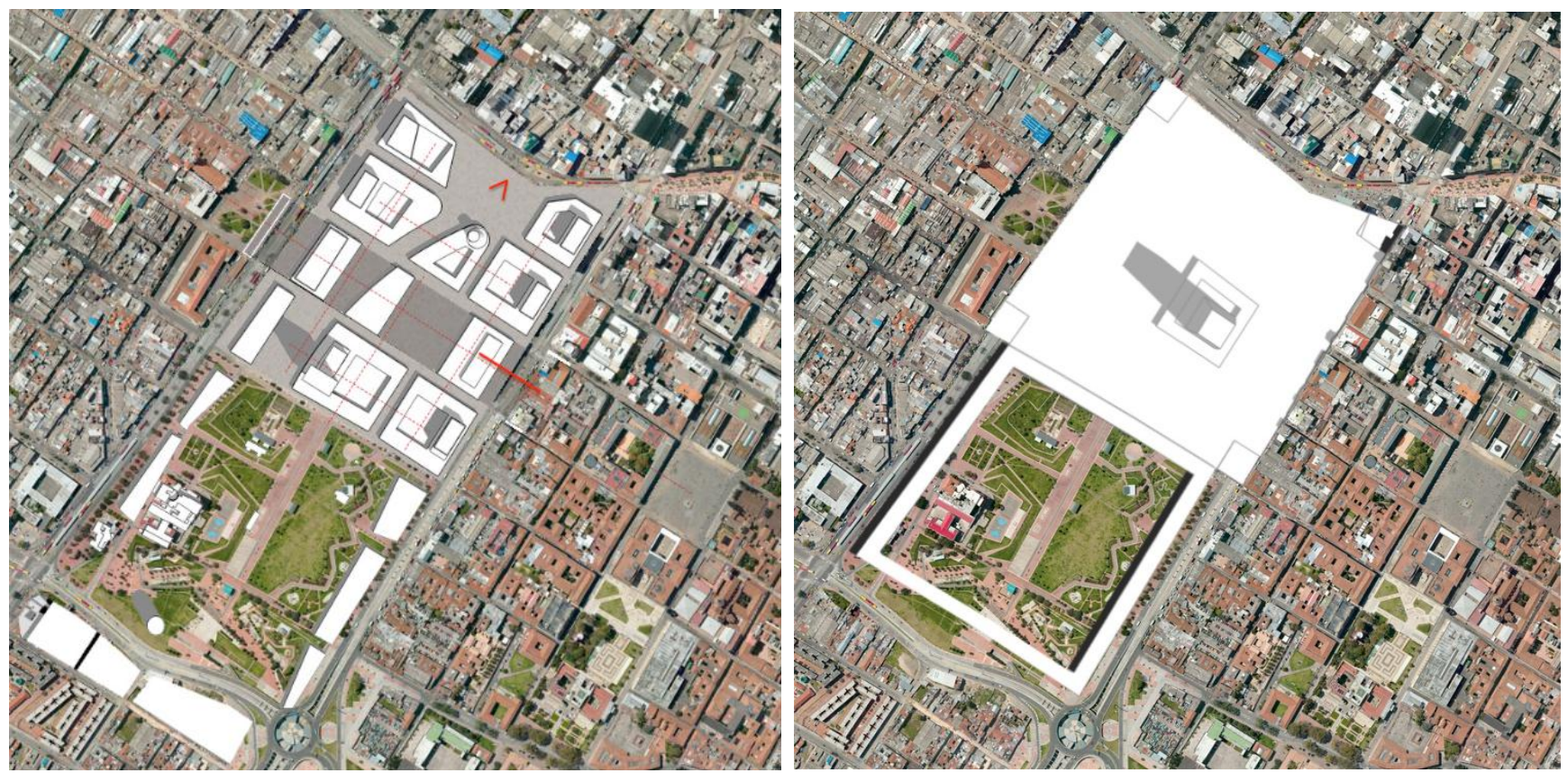

> 31. Planta de Escenario 2. Elaboración propia

$>$ 32. Planta de Escenario 5. Elaboración propia

El escenario 2, liberó estratégicamente la ocupación del espacio en la superficie, manteniendo un tejido que se relaciona conceptualmente con las tipologías de edificios y espacios urbanos estudiados sobre el mismo territorio a través de la historia. La propuesta mantiene la configuración del paramento y activa los centros de manzana con plazuelas de actividad que se interconectan con caminos alternos. Por otra parte el escenario compensa el área desocupada con la zonificación del programa, en el subsuelo y en los niveles superiores de las construcciones en altura.

La conectividad con el entorno oriental y occidental, se genera a diferencia del escenario 5 a nivel subterráneo, y en sentido oriente occidente a nivel de la superficie. La localización de las formas construidas en relación al entorno, permitió garantizar la continuidad y fluidez de la movilidad, así mismo generó nuevos espacios abiertos que equilibran la concentración de masas y se relacionan con el ritmo del entorno. El mayor resultado del escenario 2 en la evaluación final donde se sumaron los tres componentes: Retrospectiva, Radiografía y Configuración Espacial, se debe a que este escenario responde a factores de la vida urbana y realidad actual, que figuran como adicionales al problema de la congestión.

El escenario 5 representado en el gráfico 32, se compone de tres elementos principales: la torre, la plataforma y el edificio continuo. El programa del escenario se desarrolla principalmente en el subsuelo y en los niveles superiores de la torre, permitiendo liberar la superficie, que funciona como una plataforma peatonal continua, que integra el entorno y permite multiplicar las opciones de conectividad peatonal entre las calles, aunque a una escala monumental. La organización y zonificación vertical de los medios de movilidad, permiten que el escenario presente mayor dinámica en la fluidez, y por lo tanto en el equilibrio de la concentración de masas en el espacio libre; razón por la cual, el escenario responde a la descongestión de San Victorino. 


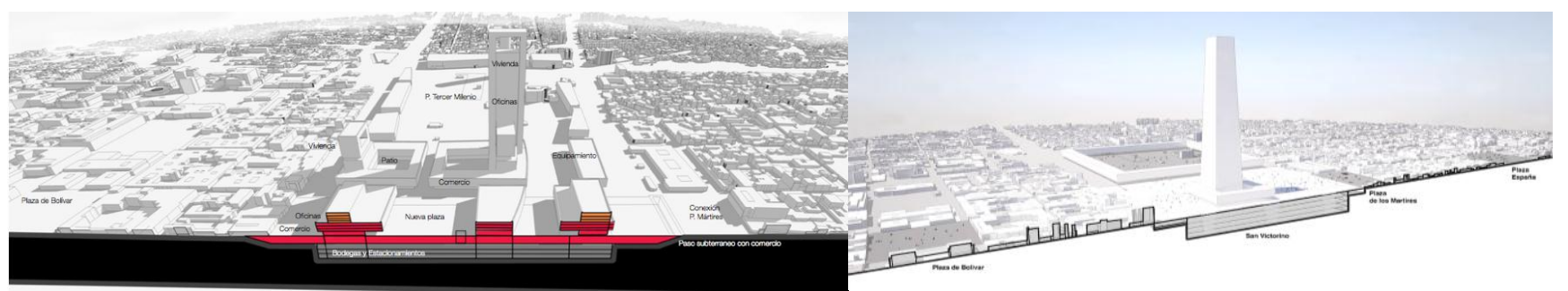

$>$ 33. Corte oriente-occidente, vista hacia el norte de escenario 2. Elaboración propia

$>34$. Corte oriente-occidente, vista hacia el norte de escenario 5. Elaboración propia

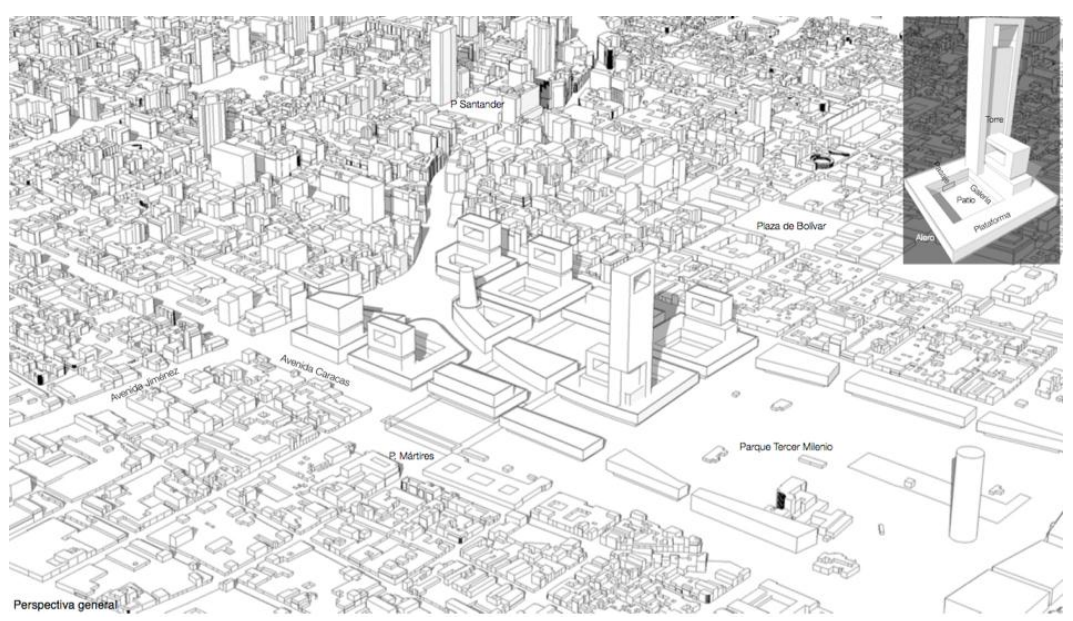

> 35. Perspectiva de Escenario 2. Elaboración propia

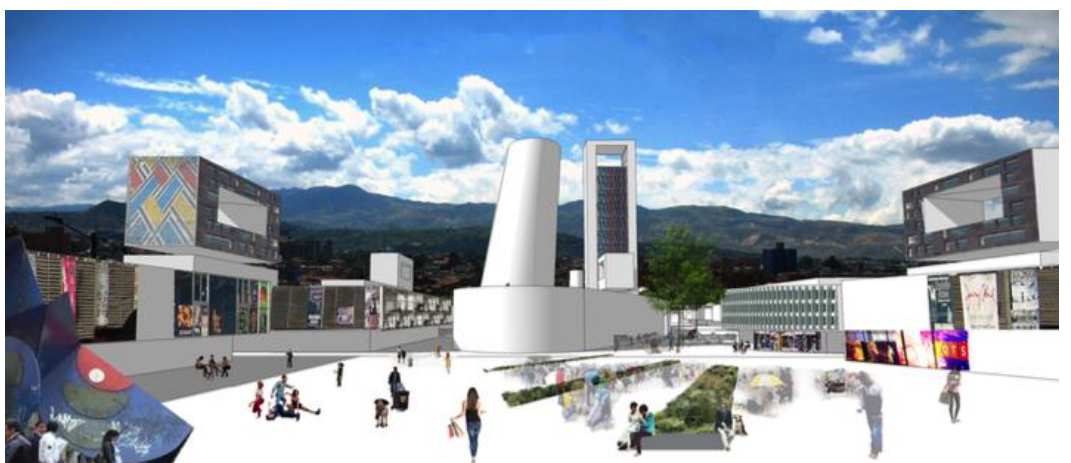

$>$ 36. Vista hacia el sur de Escenario 2. Elaboración propia

En relación al objetivo de ejemplificar como transformar la forma urbana de un área congestionada de Bogotá, en este caso de San Victorino, el escenario 2 responde con una estructura espacial equilibrada, que se evidenció con la aplicación del análisis de segmentos con medidas de integración y elección, que revela como la estructura espacial local presenta segmentos continuos integrados, que conectan espacios potenciales para recibir e intercambiar las masas que se acumulan actualmente en San Victorino.

\section{DISCUSIÓN (conclusiones y reflexiones):}

Como introducción a la discusión, se concluye en los siguientes argumentos principales:

- La congestión en el espacio urbano se genera principalmente, debido a la configuración espacial general del la ciudad, por lo tanto una modificación de escala local a la estructura no soluciona el problema de forma inmediata.

- La congestión en San Victorino se generó como resultado de un proceso histórico. 
- A partir de la configuración espacial, es posible modificar la forma como nos desplazamos y aglomeramos en el espacio, esto permite transformar el problema de la congestión.

- La organización de actividades en el espacio urbano esta ligada a la forma urbana, y a la manera como nos movemos en relación de un espacio a otro. La optimización de esta relación permite disminuir la acumulación, y evitar la congestión.

- El problema de la congestión urbana abordado individualmente puede generar resultados ajenos a otras dimensiones del diseño urbano, para relacionar la solución a estas dimensiones, como: la historia, el confort, la factibilidad de gestión, la escala humana, etc., es necesario incluirlas de forma cíclica al proceso de diseño.

A continuación se discuten las conclusiones y reflexiones generales:

- Como resultado del análisis de configuración espacial se evidenció que la estructura espacial de la ciudad funciona de manera integral, es decir, la modificación de uno de sus elementos tiene influencia general en el sistema. En este sentido la modificación sectorial de la estructura no soluciona el problema de la congestión de forma inmediata, no obstante, puede inducir gradualmente en el tiempo al cambio del sistema espacial en ámbitos mayores, que pueden mejorar la fluidez general de la movilidad en la ciudad a larga distancia por medio motorizado, y a corta distancia por medio peatonal.

- La integración equilibrada de las partes, de la estructura espacial del sector de San Victorino en una distancia caminable, puede mejorar la fluidez y aportar a la descongestión urbana. Como resultado del análisis de segmentos con las herramientas de Space Syntax, se propuso la configuración de estructuras espaciales más equilibradas en relación a la medición de integración y elección. Con esto se buscó un mayor equilibrio entre segmentos con rangos de mayor y menor integración-elección, lo cual garantiza el movimiento e interés de la gente repartido equitativamente en el espacio, disminuyendo la tendencia a la acumulación. La estrategia para la configuración espacial no debe buscar que se pierdan las jerarquías, debe buscar que se equilibren.

- En el análisis sintáctico que se aplicó a la ciudad de Bogotá, se evidenció que el centro de Bogotá tienen la cualidad espacial de estar altamente integrado, lo cual hace que exista atracción de personas y movimiento intenso de intercambio, y relaciones entre la gente. Espacialmente esta intensidad requiere del mayor aprovechamiento del espacio y lógica en la movilidad de múltiples medios para evitar la congestión. En este sentido, la aplicación de estrategias desarrolladas preliminarmente en este trabajo como: fluidez, desocupar, colonizar el subsuelo, colonizar el espacio aéreo, conectar nuevos sistemas con la trama espacial existente, etc.; son prioridades para inducir la solución a el problema.

El resultado lógico de la aplicación de estas estrategias es susceptible a perder la sensación de escala humana. Particularmente en Bogotá, en San Victorino, como se demostró con los análisis de configuración espacial, la solución parcial a la conectividad equilibrada mejora con cambios considerables de escala y complejidad.

- La estructura espacial de la ciudad se comporta de manera integral, la modificación de la configuración espacial de San Victorino influye en su entorno en relación a la accesibilidad que propaga la acumulación o repulsión de personas modificando la congestión. La modificación tiene influencia en diferentes escalas que dependen del medio de movilidad, por ejemplo, en un radio de 10.000 metros el medio es motorizado y en un radio de 800 metros el medio puede ser peatonal.

- La historia permite entender la formación de los fenómenos que ocurren en la ciudad, transmitiendo las causas y evidenciando los momentos de transformación negativa y positiva que aportan en la construcción de criterios sólidos para la transformación o solución de los problemas. Las estrategias empleadas en el proceso de diseño de escenarios, para este trabajo están cargadas de los aportes de la historia, en relación a lo irrepetible y lo replicable. 
- Este trabajo se considera parte de un proceso de entendimiento y transformación de un fenómeno y problema analizado principalmente con herramientas de bases científicas, como las de Space Syntax, que dieron como resultado posibles soluciones por medio de la forma urbana, como fue el caso del la opción de mayor escala y menor ocupación del espacio (escenario 5). En este sentido se considera relevante dar continuidad al análisis, incluyendo criterios de la vida urbana, que profundicen, equilibren el resultado, y lo acerquen a la sociedad actual, aunque sin desconocer los efectos de problemas y fenómenos que han producido las grandes ciudades actuales, como se evidenció con el caso de la congestión en el espacio urbano. En este marco se sugiere dar continuidad a este trabajo con el desarrollo de una estrategia adicional relacionada al tema de la vida urbana y el diseño para los sentidos, que puede servir de complemento.

- El comercio de San Victorino funciona en espacios de venta reducidos, que exigen la mayor cantidad de frentes posibles en el área de la manzana colonial de tipo $100 \times 100$ metros aproximadamente. En el análisis de configuración espacial se encontró que el escenario número 4 es el que mayor cantidad de segmentos integrados tiene, y presenta mayor área de frentes de fachada en el área específica de San Victorino.

Mayor integración y mayor frente de fachadas, se traduce en atracción de mayor cantidad de personas y mayor ocupación del suelo, propagando la congestión en la escala local. En este sentido se concluye que la integración de segmentos debe ser repartida de forma equilibrada en radios de distancia caminable cercanos a los 800 metros.

En el análisis comparativo de escenarios, se puede presentar similitud en el valor de integración alta para dos escenarios con distribución de segmentos distinta en el sistema espacial. En relación a la congestión, un escenario puede ser propagador de congestión y otro descongestionante, es decir, cuando la organización de los segmentos se distribuye de forma equilibrada en el espacio la estructura tiende a ser fluida, no obstante, cuando los segmentos se concentran significativamente la estructura tiende a ser congestionada. Debido a lo anterior, la calificación de escenarios se hizo en base a la proximidad de los segmentos a la línea media entre la integración y la elección, y no de acuerdo al resultado mayor de una de las dos medidas de integración y elección.

- El escenario \# 2, en el análisis de configuración espacial presentó equilibrio en las medidas de integración y elección en la escala zonal, adicionalmente presentó la mayor rentabilidad con los uso propuestos, y recogió una alta cantidad de elementos históricos de referencia en su concepción. Debido a lo anterior se ubico como el escenario mayormente viable.

- El resultado de esta investigación, sugiere que el estudio específico del espacio, es de la mayor relevancia para solucionar problemas y fenómenos propios de la ciudad, que actualmente son potenciados por exigencias normativas o abordados desde otras disciplinas

\section{BIBLIOGRAFÍA}

AL_SAYED, K., TURNER, A., HILLIER, B., SHINICHI, L., \& PENN, A. (2014). Space Syntax Methodology (4th edition ed.). London: Barttlet School of Architecture, UCL.

ARANGO CARDINAL, S. (2012). Ciudad y Arquitectura. Seis generaciones que construyeron la América Latina moderna. México: Ediciones fondo de cultura económica Colombia.

CARBONELL HIGUERA, C. M. (2010). El sector de San Victorino en los procesos de reconfiguración urbana de Bogotá. Cuadernos de Vivienda y Urbanismo , 3 (6), 220-245.

CULLEN, G. (1974). Townscape. London: Architectural Press.

GEHL, J. (2010). Cities for people. Washington: Island Press.

GEHL, J., \& SVARRE, B. (2013). How to Study Public Life. Washington: Island Press.

HALL, E. T. (1969). The hidden dimension. New York: Anchor books.

HILLER, B., \& HANSON, J. (1984). The Social Logic of Space. New York: Cambridge University Press. 
HILLIER, B. (1999). Centrality as a Process: Accounting for attraction inequalities in deformed grids. URBAN DESIGN International , 4, 107-127. (1996). Space is the Machine. Londres: Cambridge University Press.

INSTITUTO DISTRITAL DE PATRIMONIO CULTURAL . (2012). Fray Domingo de Petrés: En el Nuevo Reino de Granada. Bogotá: IDPC.

JACOBS, J. (2013). Muerte y vida de las grandes ciudades (Tercera edición ed.). (Á. Abad, Trad.) Madrid: Capitan Swing Libros.

JARAMILLO, S. (2006). Reflexiones sobre las políticas de recuperación del centro - y del centro histórico - de Bogotá (Primera Edición ed.). Bogotá: Universidade de los Andes, Facultad de Economía, CEDE.

KAIJIMA, M., KURODA, J., \& TSUKAMOTO, Y. (2015). Made in Tokio. Tokio: Kajima Institute Publishing Co. Ltd.

KOOLHAAS, R. (1994). Delirious New York. New York: The Monacelli Press.

LECORBUSIER. (1987). The city of tomorrow and its planning. NewYork: Dover Publications, INC.

LYNCH, K. (1960). The Image of the city. Cambridge, Massachusetts, Estados Unidos de América: The MIT Press.

MARTÍNEZ, C. (1978). Bogotá: Reseñada por cronistas y viajeros ilustres 1572-1948. Bogotá: Escala. (1976). Bogotá: Sinópsis sobre su evolución urbana, 1536-1900. Bogota: Escala.

(1987). Santafé: Capital del Nuevo Reino de Granada. Bogotá: Ediciones PROA.

MEJíA PAVONY, G. R. (2000). Los años de cambio: historia urbana de Bogotá, 1820 - 1910 (2a ed. ed.). Bogotá: CEJA.

MORENO DE ÁNGEL, P., \& MELO GONZÁLEZ, J. O. (1995). Caminos Reales de Colombia. (M. U. Losada, Ed.) Fondo FEN Colombia.

NIÑO MURCIA, C., \& REINA MENDOZA, S. (2014). La carrera de la modernidad: construcción de la carrera décima, Bogotá 1945-1960 (Segunda edición ed.). Bogotá: Instituto distrital de patrimonio cultural.

PRIETO RUIZ, B. (2011). El madrugón en San Victorino: una exploración a los ordenes sociales asociados a este mercado textil popular. Bogotá: Editorial Universidad del Rosario.

REM KOOLHAAS AND HARVARD DESIGN SCHOOL PROJECT ON THE CITY. (2001). Mutations. Barcelona: Actar.

RODRíGUEZ GÓMEZ, J. C. (2012). Acueducto de Bogotá, 1887 - 1914: Entre lo público y lo privado. Credencial Historia (267).

ROSA, M. D. (1938). Calles de Santafé de Bogotá. Bogotá: Ediciones del concejo.

SABOGAL BERNAL, S. (2013). Imagen y memoria de la transformación urbana de San Victorino. Bogotá: Universidad Nacional de Colombia. Facultad de Artes.

STRAUSS, C. L. (1967). Structural Anthropology (Vol. vol.1). New York: Anchor Books.

The Harvard Graduate School of Design and OMA. (2001). Project on the city II: The Harvard Guide to Shopping. Taschen.

VARGAS LESMES, J., \& ZAMBRANO PANTOJA, F. (1988). Bogotá 450 Años: retos y relaidades. Bogotá: Foro Nacional por Colombia.

WHYTE , W. (1980). The Social Life of Small Urban Spaces. Washington: Conservation fundation. 